\title{
La estratificación social \\ bajo tensión en la era de la globalización
}

\section{Emilio Klein}

Sociólogo, Equipo Técnico

Multidisciplinario

Organización Internacional

del Trabajo (оIт)

klein@oitchile.cl

\section{Víctor Tokman}

Director Regional para

las Américas

oIT, Santiago de Chile

tokmansc@oitchile.cl

El objetivo de este trabajo es explorar el efecto de la globalización en el mercado del trabajo y en la estratificación social. Hay consenso en que la globalización traerá consigo el progreso para los pueblos y las naciones. Sin embargo, la experiencia de casi 20 años suscita dudas crecientes acerca de sus beneficios potenciales netos $\mathrm{y}$, particularmente, de la distribución de esos beneficios. Como es evidente, hay ganadores y perdedores en ese proceso, tanto entre los países como entre las personas. Este artículo se concentrará en los efectos sobre las personas dentro de cada país y se referirá a una sola región: América Latina. Intentará identificar a los ganadores y a los perdedores en el proceso de globalización y, en especial, el impacto que ha tenido en la estratificación social. ¿Lleva la globalización a una mayor integración social dentro de cada nación, o conduce a la desintegración social (por el hecho de que sólo se están integrando algunos grupos mientras la mayoría se ve excluida progresivamente)? Para examinar este problema, el trabajo se divide en cuatro secciones. La primera analiza la globalización como parte integral de un bloque de políticas, pues es necesario referirse al impacto conjunto y no tratar de aislar los efectos parciales. La segunda estudia los efectos sobre el empleo, el ingreso y la equidad. La tercera explora los cambios en la estructura social asociados con algunos de los principales procesos que acompañan a la globalización. Por último, se presentan algunas conclusiones sobre la estructura social de América Latina durante el período de la reforma. 


\section{La globalización como parte de un bloque de políticas}

La globalización, en sentido estricto, se refiere a los importantes cambios ocurridos en la economía internacional en materia de comercio, finanzas e información. Este proceso no se ha dado en forma aislada, sino como parte integral de un conjunto de políticas que combinan medidas de ajuste interno con cambios en la forma de inserción de los países en la economía internacional. Tres procesos principales caracterizan el escenario emergente: la globalización, la privatización y la desregulación (Tokman, 1997). De hecho, el conjunto de políticas que adoptaron muchos países, por lo menos en América Latina, se conoce a partir de 1989 como el Consenso de Washington (Williamson, 1990).

La globalización significa que las economías nacionales están hoy más integradas con la economía internacional y que los bienes, el capital y las comunicaciones, así como las personas, se han acercado más que nunca antes. Esto ha sido resultado de la apertura de las economías y también del rápido cambio tecnológico. La liberalización del comercio y de las finanzas ha sido consecuencia de la reducción de los aranceles y las barreras no arancelarias mediante i) acuerdos multilaterales en el marco del Acuerdo General sobre Aranceles Aduaneros y Comercio (GATT) y la creación de su sucesora, la Organización Mundial del Comercio (омс); ii) sistemas de integración, nuevos o reactivados, como el Tratado de Libre Comercio de América del Norte (TLC) y la asociación de libre comercio de América del Sur conocida como Mercosur; iii) la proliferación de acuerdos de comercio bilaterales en los últimos años; y, lo más importante, iv) la reducción unilateral de aranceles, como componente clave del conjunto de políticas de ajuste. Los aranceles latinoamericanos se redujeron desde un promedio de entre $35 \%$ y $100 \%$ (para niveles mínimos y máximos) en 1985 , a uno de entre $14 \%$ y $22 \%$ a principios del decenio de 1990. La diversificación de la estructura arancelaria se redujo también en forma importante, y hoy se limita en la mayoría de los países a no más de tres categorías (Tokman, 1999).

$\square$ Una versión preliminar de este trabajo se preparó a solicitud del PNUD como contribución al Informe sobre el desarrollo humano, 1999.
La globalización abre nuevas posibilidades para el crecimiento y la creación de empleos, pero a la vez afecta los factores determinantes del empleo y los salarios y necesita regulación para evitar la competencia internacional desleal. Dadas las diferencias en dotación de recursos, se espera que las exportaciones de los países en desarrollo a los desarrollados se concentren en bienes que requieran uso intensivo de mano de obra no calificada. Esto podría aumentar la demanda de esos tipos de trabajo y reducir la brecha entre las remuneraciones de la mano de obra calificada y no calificada.

Esta expectativa podría también combinarse con las diferencias vigentes de remuneración y regulación laboral entre países, para generar una expansión del comercio basada en prácticas laborales desleales o una mayor explotación de los trabajadores. En torno a este tema se ha suscitado un debate en el plano internacional sobre cómo evitar que esto suceda y si es necesario introducir normas adicionales. Aunque no hay consenso respecto de cómo proceder, es evidente que nadie postula la igualación de los salarios entre distintos países por el efecto que podría tener en la capacidad competitiva de los países en desarrollo, ni se acepta que la expansión del comercio deba basarse en la explotación del trabajo. Se ha discutido, asimismo, la posibilidad de aplicar sanciones a quienes no cumplen con las normas laborales internacionales mínimas, pero, hasta ahora, no han sido aceptadas por el riesgo de abusar de ellas como instrumento de protección comercial. Hay, sin embargo mayor consenso sobre la necesidad de instituir la vigilancia internacional y nacional sobre el grado de progreso social que acompaña al progreso económico y, particularmente, sobre el cumplimiento de las normas laborales básicas por todos los socios comerciales. Esto ha sido incorporado en la Declaración de la ort relativa a los Principios y Derechos Fundamentales en el Trabajo, y su seguimiento, aprobada por la Conferencia Internacional del Trabajo el 18 de junio de 1998 .

La globalización afecta también a los determinantes de la creación de empleos y los salarios, porque en las economías abiertas la capacidad para competir llega a ser un factor importantísimo, lo que restringe los ajustes salariales. A diferencia del ambiente económi- 
co anterior, es necesario ahora un vínculo más estrecho entre la productividad y los salarios. En las economías cerradas, los aumentos de salarios que exceden el crecimiento de la productividad pueden ser transferidos a los precios, lo que provoca inflación; en las economías abiertas el resultado es una menor capacidad de competencia. Además, las fluctuaciones de la demanda exigen una capacidad más rápida para adaptarse y una mayor flexibilidad en los procesos de producción y laborales.

La privatización es la segunda característica de este nuevo escenario. La privatización disminuye el tamaño y las funciones del gobierno y aumenta la importancia del sector privado y los mercados en la administración y asignación de los recursos. El empleo público naturalmente cae, la racionalización que emprenden los nuevos dueños disminuye el empleo total y las empresas públicas se transfieren a capitalistas nacionales o internacionales. Lo anterior es resultado de la necesidad de reducir los déficit fiscales durante el ajuste. Además, la responsabilidad de invertir se transfiere crecientemente al sector privado, restringiendo la inversión pública a la social y de infraestructura básica, con una participación creciente del sector privado en la ejecución y gestión.

La desregulación es el tercer proceso introducido en el nuevo escenario. Esto ha significado reducir la protección y la intervención del gobierno en el comercio, las finanzas y los mercados de trabajo. Como se dijo, la liberalización comercial y financiera está llevando a una mayor globalización, mientras se reduce la protección a los mercados de productos y del trabajo para aumentar la eficiencia económica y para permitir una mayor influencia de los mercados en la asignación de los recursos. El proceso de desregulación ha sido promovido, en parte, por grandes reformas jurídicas, pero también ha habido un importante aumento espontáneo de la flexibilidad por efecto de la operación irrestricta de los mercados.

El triple proceso de globalización, privatización y desregulación se está dando en un medio internacional caracterizado por la universalización de los problemas económicos y sociales y por una homogeneidad ideológica creciente. Hoy, los problemas del empleo y la exclusión social ya no están presentes sólo en los países en desarrollo, sino que afectan incluso a las economías más desarrolladas del mundo. En algunos países industrializados de la Organización de Cooperación y Desarrollo Económicos (OCDE) el alto desempleo es un fenómeno irreductible: más de treinta millones de personas se clasifican oficialmente como cesantes, mientras otros 10 millones no están ya buscando trabajo en forma activa (OCDE, 1994, y OIT, 1996). En promedio, el desempleo sobrepasa el $10 \% \mathrm{y}$, en muchos países, uno de cada cinco trabajadores en algunos grupos vulnerables —como los jóvenes- está sin trabajo. El fin de la guerra fría derribó las barreras ideológicas, y los conflictos actuales son provocados, no tanto por divergencias de postura, sino más bien por los intereses locales o la reacción natural ante los costos sociales del ajuste.

Los tres procesos están relacionados entre sí, tanto en términos teóricos como prácticos. Por el lado analítico, la globalización no podría haber avanzado si no hubiese estado acompañada por otros componentes del ajuste, que reducen la protección comercial, así como por la liberalización financiera y la privatización, que abren posibilidades de crecimiento del comercio, de las corrientes de capitales y de la inversión extranjera directa. Todas estas políticas contribuían a lograr el equilibrio macroeconómico, pero también eran condiciones necesarias para la integración en la economía mundial. Estos conjuntos de políticas fueron incorporados plenamente en el Consenso de Washington, con la adición de instrumentos para lograr la disciplina fiscal. Estos últimos se incluyeron con el objetivo principal de garantizar la estabilidad de los precios, pero desempeñan también un papel importante en la creación de incentivos a la entrada de capitales en un esquema más estable. Lo que no ha sido liberalizado es el movimiento de trabajadores no calificados. Sólo se introdujeron políticas de regularización ex post facto para la migración ilegal, pero la política sigue siendo de fronteras cerradas o al menos de regulación estricta de esas corrientes.

La historia económica reciente de los países de América Latina muestra que la globalización ha estado acompañada por la privatización y la desregulación. La programación y la mezcla de políticas han variado según los países y es quizás prematuro evaluar sus resultados. Sólo cinco países —Brasil, Chile, Colombia, Costa Rica y Uruguay - han alcanzado un nivel de ingreso por habitante más alto que el del período anterior a la crisis. Aún menos países fueron capaces de lograr una tasa de crecimiento alta y sostenida; Chile y Colombia fueron los únicos que pudieron crecer en más de un 5\% anual durante cuatro años consecutivos. Las tasas de crecimiento han sido irregulares, prevaleciendo ciclos de intermitencia. Además, otras características influyeron en los resultados. Las condiciones iniciales de cada país eran diferentes: algunos empezaron el proceso de reforma en época temprana mien- 
tras que otros lo hicieron a fines de los años ochenta o principios de los noventa. La combinación de políticas en cada etapa fue también distinta.

A pesar de las diferencias, después de quince años de ajuste puede concluirse que todos los países de América Latina estuvieron involucrados en el proceso de globalización y ajuste, y que la privatización y la desregulación eran parte integral del conjunto de polí- ticas. Los resultados no están claros todavía y los instrumentos de política evolucionan constantemente, pero es evidente que la región está hoy más abierta e integrada en la economía mundial, más privatizada y menos regulada que antes de 1980. Todo esto sucedió en forma simultánea; así, cualquier análisis de los resultados debería incorporar el contexto. Es lo que haremos en lo que sigue de este trabajo.

\section{II}

\section{Empleo, ingresos y equidad en la globalización}

\section{El efecto esperado}

Se espera que la globalización genere dos efectos principales en el trabajo y los ingresos. Primero, el aumento de la productividad, especialmente en los sectores de bienes transables, debería traducirse en aumentos del empleo y reducciones de precios en esos sectores. Esto último debería traducirse también en una expansión del ingreso real y del bienestar de la población. Segundo, el aumento de los salarios en los sectores exportadores, que se supone hacen uso menos intensivo de mano de obra no calificada, debería provocar una reducción de las diferencias de salarios por niveles de capacitación $\mathrm{y}$, con ello, aumentar la equidad.

La reducción o eliminación de los aranceles y las barreras no arancelarias deberían generar una disminución en los precios relativos de los bienes transables. Por el lado de la producción, esto se traduciría en una reasignación de factores hacia los sectores de exportación y, por el del consumo, en una reasignación del gasto hacia bienes y servicios importados. En consecuencia, el aumento de las exportaciones debería tener un efecto positivo en el empleo, en tanto que la reducción relativa de precio de los bienes importables generaría un aumento de los ingresos reales. La liberalización del comercio debería así provocar un mayor bienestar.

Sin embargo, a corto plazo, la expansión del empleo derivada del aumento de las exportaciones podría ser contrarrestado por la caída del empleo en los sectores que compiten con las importaciones. El aumento de la competencia en estos sectores obliga a las empresas a mejorar la productividad, por lo general a costa del empleo. El efecto neto de la apertura económica sobre el empleo dependerá del comporta- miento de la demanda de trabajo en los sectores de bienes transables y no transables, y en la dinámica de la oferta de trabajo. Esto afectará, a su vez, los salarios medios en cada sector.

Otro resultado esperado de la liberalización comercial es que debería producir un incremento del precio relativo de los bienes de uso intensivo de trabajo no calificado en los países en vías de desarrollo, lo que se traduciría en una mayor demanda de trabajo no calificado y un mejoramiento de sus salarios relativos. Por consiguiente, la dispersión de los salarios disminuiría. $^{1}$

\section{El resultado observado}

\section{a) Mejoramiento de la productividad y de la compe- titividad internacional}

El primer resultado esperado que se registra en la mayoría de los países es el aumento de la productividad en los sectores transables, sobre todo en la industria manufacturera. Como se verá más adelante, este resultado se asocia con una reducción del nivel de empleo en el sector. En el decenio de 1990, la productividad por empleado creció a tasas anuales de $5 \%$ a 7\% en Argentina, Brasil, México y Perú, y de alrededor de $3 \%$ en Chile.

La competitividad internacional se ve afectada de distintas maneras, según el país y los indicadores empleados para la medición de los costos del trabajo. Con frecuencia se argumenta que la sobrerremuneración del

\footnotetext{
1 Para un análisis de los fundamentos teóricos y su validación empírica en los países desarrollados, véase, entre otros, Bhagwati y Dehejia, 1993; Lawrence y Slaughter, 1993; Wood, 1994; orT, 1995; y Sachs y Shatz, 1994.
} 
trabajo puede afectar el acceso a los mercados internacionales. En efecto, en un medio más competitivo, los costos importan. La remuneración excesiva al trabajo puede ser consecuencia de salarios muy altos, de otros costos no salariales muy elevados, o de ambas cosas. La situación de la mayoría de los países latinoamericanos no parece justificar la prioridad que se le ha dado a este problema (salvo por algunos ajustes necesarios).

En la mayoría de los países latinoamericanos, a pesar de su lenta recuperación reciente, los salarios son todavía más bajos que en 1980. En promedio, los salarios mínimos en 1999 eran inferiores en $26 \%$ a los de 1980 , pero en la industria manufacturera habían subido en $2.9 \%$ en el mismo período. Los costos no salariales difieren mucho de un país a otro, situándose en un rango del $38 \%$ al $68 \%$ de los salarios. En Chile y Argentina, los costos no salariales son más elevados que en la República de Corea, similares a los de Estados Unidos, y mucho más bajos que en los países europeos de la OCDE. El costo horario de la mano de obra en la industria manufacturera de América Latina se sitúa entre 2.10 y 6.50 dólares, lo que equivale a entre un tercio y un octavo del nivel de los Estados Unidos y a una fracción aún menor del de países del sudeste asiático. Las diferencias de costo de mano de obra por unidad de producción son más pequeñas debido a la mayor productividad en los países que compiten (cuadro 1). Esto muestra la importancia mayor del mejo- ramiento de la productividad como elemento de principal prioridad para elevar la competitividad, en comparación con la reducción de costos (Tokman y Martínez, 1999).

El hecho de que los costos relativos de la mano de obra no sean elevados no es razón para no introducir algunos ajustes en la estructura de costos del trabajo con el fin de reducirlos aún más y, sobre todo, para disminuir el costo de la mano de obra no calificada. Los impuestos que gravan la mano de obra no calificada tienden a favorecer el desempleo, en tanto que algunos de los impuestos que hoy gravan la planilla serían más eficientes si se transfirieran a otras fuentes de recaudación, en particular aquellos que financian la compra de viviendas y otras inversiones.

La evolución de los costos de mano de obra en el decenio de 1990 muestra también otros aspectos de política que merecen consideración. Dichos costos, deflactados por los precios al consumidor, no crecieron más que la productividad, por ejemplo, en Argentina, Brasil, México o Perú y, por lo tanto, no limitaron el acceso a los mercado internacionales. Sin embargo, expresados en dólares, y no en moneda local, o cuando se los observa con relación a precios al productor, la situación muestra escasos avances y, en muchos casos, una pérdida de competitividad (cuadro 1). Esto es atribuible a los efectos de la política macroeconómica de ese período, que en la mayoría de los países se basaba en la sobrevaluación de las mo-

\begin{tabular}{|c|c|c|c|c|c|c|c|c|c|c|}
\hline & \multirow{3}{*}{$\begin{array}{l}\text { Salario } \\
\text { por hora } \\
\text { (dólares) }\end{array}$} & \multirow{3}{*}{$\begin{array}{c}\text { Costos } \\
\text { no salariales } \\
\text { Como \% de } \\
\text { los salarios }\end{array}$} & \multirow{3}{*}{$\begin{array}{c}\text { Costo de mano } \\
\text { de obra } \\
\text { por hora } \\
\text { (dólares) }\end{array}$} & \multirow{3}{*}{$\begin{array}{l}\text { Costos de mano } \\
\text { de obra por pieza } \\
\text { de producción } \\
\text { (Nivel de } \\
\text { EE.UU.=100) }\end{array}$} & \multicolumn{6}{|c|}{ Variaciones anuales 1990-1995 } \\
\hline & & & & & \multicolumn{2}{|c|}{$\begin{array}{c}\text { Costos de } \\
\text { mano } \\
\text { de obra } \\
\end{array}$} & \multirow[t]{2}{*}{$\begin{array}{l}\text { Produc- } \\
\text { tividad }\end{array}$} & \multicolumn{3}{|c|}{ Competitividad $^{\mathrm{b}}$} \\
\hline & & & & & $\mathrm{A}$ & $\mathrm{B}$ & & $\overline{\mathrm{A}}$ & B & $\mathrm{C}$ \\
\hline Argentina & 4.6 & 42.5 & 6.5 & 55 & -2.0 & 13.1 & 7.0 & 9.2 & -6.1 & 3.7 \\
\hline Brasil & 3.7 & 58.2 & 5.9 & 60 & 2.9 & 8.5 & 7.5 & 4.5 & -0.9 & 4.3 \\
\hline Chile & 2.5 & 38.0 & 3.5 & 43 & 4.3 & 9.4 & 3.2 & - & -5.7 & 5.9 \\
\hline México & 1.9 & 42.0 & 2.8 & 47 & 1.2 & 1.5 & 5.2 & 1.1 & 3.6 & $\ldots$ \\
\hline Perú & 1.3 & 64.3 & 2.1 & 43 & 5.1 & 11.6 & 6.6 & 4.0 & -4.5 & 0.3 \\
\hline EE.UU. & 12.6 & 40.3 & 17.7 & 100 & & 2.6 & 3.8 & 1.4 & -1.2 & $\ldots$ \\
\hline Alemania & 16.1 & 78.5 & 28.7 & 150 & & 2.1 & 1.8 & & -0.3 & $\ldots$ \\
\hline República de & & & & & & & & & & \\
\hline Corea & 6.8 & 21.9 & 8.2 & 60 & & 3.6 & 11.9 & & 8.0 & 50.0 \\
\hline
\end{tabular}

Fuente: Tokman y Martínez (1999), OIT (1998) y actualizaciones de los autores.

a Industria manufacturera, alrededor de 1997. La competitividad se define como la diferencia entre cambios en la productividad y los costos de mano de obra.

b A = Variación en moneda local a precios constantes, deflactado por el índice de precios al consumidor (1990-1995). B = Variación en dólares (1990-1995).

C = Variación en dólares, entre julio de 1997 y junio de 1998. 
nedas nacionales, por la necesidad de reducir la inflación y debido a la liberalización de las corrientes de capital. Parte de la pérdida se explica por la demora en el ajuste del tipo de cambio.

Por otro lado, los precios internos se adaptan a velocidades distintas a un medio más competitivo; los precios de los bienes transables, por lo general incluidos entre los precios al productor, se ajustan más rápidamente, en tanto que los bienes de consumo, más influidos por los bienes y servicios no transables, tienden a ajustarse más lentamente. El resultado es que, mientras los costos de mano de obra expresados en precios al consumidor no crecían, de hecho sí lo hacían muy rápidamente cuando se denominaban en términos de precios al productor. Este cambio de los precios relativos, aunque ajeno al mercado de trabajo, sí influye en la dinámica de la determinación de los salarios, puesto que genera perspectivas diferentes para los trabajadores (basadas en el poder adquisitivo de los salarios) y para los empresarios (basadas en el margen de utilidad).

Más aún, como se aprecia claramente desde mediados de 1997, la competitividad depende también de cambios en otros países. No obstante el aumento de la competitividad de los países latinoamericanos de $0.4 \%$ a $10 \%$, su capacidad para competir con bienes provenientes de países asiáticos se deterioró. El mejoramiento de la productividad de esos países fue de alrededor de $50 \%$-entre $20 \%$ en Tailandia y $60 \%$ en Malasiaen comparación con el mayor incremento de América Latina de alrededor de un 10\%, registrado en Colombia.

En suma, como era de esperarse, la productividad creció como resultado del proceso de reforma, pero todavía se requieren algunos ajustes. Primero, para mantener la competitividad internacional, deberían examinarse los costos no salariales. Segundo, deberían revisarse las políticas macroeconómicas, sobre todo la sobrevaluación de los tipos de cambio y los precios relativos. Por último, los avances de la productividad no fueron suficientes para alcanzar a los competidores.

\section{b) Creación de empleos}

Un segundo efecto de la globalización es la creación insuficiente de empleos con relación al rápido crecimiento de la población económicamente activa (PEA). En promedio, la PEA no agrícola ha crecido 3\% por año, en parte gracias a la participación creciente de la mujer en la economía salarial (cuadro 2). La creación de puestos de trabajo se retardó debido al lento e irregular crecimiento económico, lo que ha redundado en un aumento del desempleo.
En promedio, la tasa de desempleo de América Latina aumentó del $6.7 \%$ en 1980 al $8.7 \%$ en 1983 , durante la primera fase del ajuste. El desempleo disminuyó desde 1983 hasta 1992, pero nunca llegó al nivel de 1980. Después de 1992, creció en forma continua, llegando al 8.8\% en 1999 (cuadro 2). Este comportamiento no sólo muestra cuán limitada es la capacidad para reducirlo, sino también una mayor vulnerabilidad, ya que los ajustes continuos implican volver a los elevados niveles de desempleo anteriores. Hacia 1999, el desempleo latinoamericano retomaba los niveles altos de mediados del decenio de 1980.

Cuatro aspectos deben tomarse en cuenta para evaluar la forma en que el desempleo afecta a la población en América Latina. El primero es que el nivel, por sí solo, puede mal interpretarse si se compara, por ejemplo, con las tasas superiores a $10 \%$ de algunos países de la OCDE. La mayoría de los países latinoamericanos carece de seguro de desempleo y la protección está generalmente vinculada con la ocupación. No tener trabajo significa no tener ingresos y estar desprotegido. Esta es una fuente principal de exclusión social. En segundo lugar, el desempleo afecta más a las mujeres y a los jóvenes. Mientras la tasa de desempleo de las mujeres es aproximadamente un 30\% más alta que el promedio, la de los jóvenes habitualmente duplica el nivel nacional. No es raro que una vasta proporción de los excluidos sean mujeres y jóvenes. En tercer lugar, hay también grandes variaciones regionales dentro de cada país. El ajuste tiende a afectar en forma desproporcionada a aquellos lugares en que hay sectores claves que necesitan reestructurarse. Por lo general estas actividades constituyen la fuente principal de empleo y producción, y su reestructuración afecta a toda la región.

La situación también difiere de un país a otro. El tamaño, el grado de modernización y la etapa del proceso de reforma en que se encuentran son factores determinantes en relación con el desempleo. Las economías pequeñas y abiertas son más vulnerables a las fluctuaciones externas y en ellas las tasas de desempleo tienden a ser más altas e irregulares que en las economías más grandes y más cerradas (donde la demanda interna desempeña el papel principal y proporciona una mayor autonomía). Por otro lado, en los países en etapa de urbanización y modernización avanzada, el desempleo se convierte en la principal fuente de ajuste en los mercados de trabajo, mientras que en aquellos de gran población agrícola o de un sector formal pequeño la principal variable de ajuste la constituye el subempleo. Por último, también importa la etapa del proceso de reforma. Los primeros reforma- 
CUADRO 2

América Latina: Actividad económica, empleo, salarios y pobreza

(Indice y tasas anuales de crecimiento)

\begin{tabular}{|c|c|c|c|c|c|}
\hline Indicador & 1980 & 1985 & 1990 & 1995 & 1999 \\
\hline \multicolumn{6}{|l|}{ Actividad económica } \\
\hline $\mathrm{PNB}^{\mathrm{a}}$ & $\ldots$ & 0.6 & 1.9 & 2.9 & $\ldots$ \\
\hline PNB per cápita ${ }^{a}$ & $\ldots$ & -1.6 & -0.1 & 1.1 & -1.8 \\
\hline Inflación ${ }^{\mathrm{a}}$ & $\cdots$ & 134.8 & 487.5 & 287.5 & 9.8 \\
\hline \multicolumn{6}{|l|}{ Población y empleo } \\
\hline PEA total ${ }^{\mathrm{a}}$ & $\ldots$ & 3.5 & 3.1 & 2.6 & 2.6 \\
\hline PEA urbana $(\%)$ & 66.9 & 70.0 & 72.8 & 75.3 & 76.6 \\
\hline Empleo no agrícola ${ }^{a}$ & $\ldots$ & 3.5 & 4.4 & 3.0 & 2.8 \\
\hline Tasa de desempleo abierto & 6.7 & 10.1 & 8.0 & 7.2 & 8.8 \\
\hline Informalidad $(\%)^{\mathrm{b}}$ & 40.2 & 47.0 & 44.4 & 46.5 & 48.5 \\
\hline Empleo sector público $(\%)^{\mathrm{c}}$ & 15.7 & 16.6 & 15.5 & 13.4 & 13.0 \\
\hline Salarios reales de la manufactura & 100.0 & 93.1 & 86.6 & 92.4 & 102.9 \\
\hline Salarios mínimos reales & 100.0 & 86.4 & 68.4 & 70.8 & 73.8 \\
\hline \multicolumn{6}{|l|}{ Pobreza } \\
\hline Porcentaje de hogares pobres $(\%)$ & 35.0 & 37.0 & 41.0 & 38.0 & 36.0 \\
\hline Urbanización de la pobreza (\%) & 71.4 & $\ldots$ & 85.4 & 84.2 & $83.3^{\mathrm{e}}$ \\
\hline
\end{tabular}

Fuente: OIT, sobre la base de estadísticas nacionales.

a Tasas anuales de crecimiento.

b Porcentaje del empleo urbano.

c Porcentaje del total de la PEA.

d Índice $1980=100$.

e Cifras de 1997. dores tuvieron más éxito en reducir el desempleo, mientras que los últimos - sobre todo los que hoy se encuentran recién en las primeras fases del ajustetienden a registrar tasas de desempleo más altas y crecientes.

\section{c) Cambios en la estructura del empleo}

Además de una tasa de desempleo más alta, la reforma ha producido cambios profundos en la estructura del empleo. Se pueden identificar cuatro procesos principales relacionados entre sí: privatización, terciarización, informalización y precarización. Estos procesos se observan en el decenio de 1990, cuando la mayoría de los países han superado ya los procesos de ajuste o los tienen muy avanzados.

La privatización introdujo un cambio de comportamiento significativo en la creación de empleos en América Latina, dado el papel histórico del sector público como empleador de último recurso (como se verá en la sección siguiente) y como contribuyente importante al desarrollo de las clases medias. El gobierno no contribuyó directamente a la creación de empleos en el decenio de 1990. Por el contrario, su participación en el empleo urbano cayó para el conjunto de la región desde el $15.5 \%$ en 1990 al 13.0\% en 1999. Esta disminución no incluye la reducción del empleo público que ocurrió en períodos anteriores, por ejemplo en Chile. Este cambio del empleo público al empleo privado se dio en todos los países, y en algunos - Panamá, Argentina y Costa Rica - la baja alcanzó a niveles de entre 5 y 10 puntos porcentuales.

El traspaso del empleo del sector público al privado fue consecuencia directa de los procesos de privatización y desregulación que acompañaron a la globalización. Las empresas estatales fueron transferidas y las funciones del gobierno se redujeron. Fue también resultado importante de la disciplina fiscal, notable componente de la política de estabilización. Por lo general se reducía el déficit fiscal recortando el gasto público, principalmente la planilla, en una secuencia de reducción de salarios y empleos (cuadro 3).

La transferencia de empleos no fue, en general, hacia empresas privadas de mayor tamaño. Estas disminuyeron su participación en el empleo total durante el mismo período, aunque menos que el gobierno. Entre 1990 y 1998, la participación de estas em- 
CUADRO 3

América Latina: Estructura del empleo urbano, 1990 y 1998

(Porcentajes)

\begin{tabular}{|c|c|c|c|c|c|c|c|c|}
\hline \multirow{2}{*}{$\begin{array}{l}\text { País } \\
\text { y años }\end{array}$} & & \multicolumn{4}{|c|}{ Sector informal } & \multicolumn{3}{|c|}{ Sector formal } \\
\hline & & Total & $\begin{array}{c}\text { Trabajadores } \\
\text { por cuenta propia }{ }^{\mathrm{a}}\end{array}$ & $\begin{array}{l}\text { Servicio } \\
\text { doméstico }\end{array}$ & $\begin{array}{l}\text { Microem- } \\
\text { presas }^{b}\end{array}$ & Total & $\begin{array}{l}\text { Sector } \\
\text { público }\end{array}$ & $\begin{array}{l}\text { Empresas privadas, } \\
\text { todas }^{\mathrm{c}}\end{array}$ \\
\hline \multicolumn{9}{|c|}{ América Latina } \\
\hline \multirow[t]{3}{*}{1990} & Total & 44.4 & 23.4 & 5.7 & 15.2 & 55.6 & 15.5 & 40.1 \\
\hline & Hombres & 41.2 & 22.8 & 0.5 & 17.9 & 58.8 & & \\
\hline & Mujeres & 49.2 & 24.4 & 14.1 & 10.7 & 50.8 & & \\
\hline \multirow[t]{3}{*}{1998} & Total & 47.9 & 24.7 & 6.9 & 16.3 & 52.1 & 13.0 & 39.1 \\
\hline & Hombres & 45.0 & 24.9 & 0.6 & 19.6 & 55.0 & & \\
\hline & Mujeres & 52.0 & 24.4 & 16.0 & 11.6 & 48.0 & & \\
\hline \multicolumn{9}{|c|}{ Argentina } \\
\hline \multirow[t]{3}{*}{1990} & Total & 52.0 & 27.5 & 5.7 & 18.8 & 48.0 & 19.3 & 28.7 \\
\hline & Hombres & 49.8 & 28.2 & 0.5 & 21.2 & 50.2 & & \\
\hline & Mujeres & 55.5 & 26.5 & 14.3 & 14.7 & 44.5 & & \\
\hline \multirow[t]{3}{*}{1998} & Total & 49.3 & 22.7 & 6.4 & 20.3 & 50.7 & 12.7 & 38.0 \\
\hline & Hombres & 48.0 & 24.1 & 0.3 & 23.6 & 52.0 & & \\
\hline & Mujeres & 51.4 & 20.4 & 15.8 & 15.2 & 48.6 & & \\
\hline \multicolumn{9}{|l|}{ Brasil } \\
\hline \multirow[t]{3}{*}{1990} & Total & 40.6 & 20.3 & 6.9 & 13.5 & 59.4 & 11.0 & 48.4 \\
\hline & Hombres & 36.1 & 19.6 & 0.5 & 16.0 & 63.9 & & \\
\hline & Mujeres & 47.6 & 21.3 & 16.7 & 9.6 & 52.4 & & \\
\hline \multirow[t]{3}{*}{1998} & Total & 46.7 & 23.2 & 9.5 & 14.0 & 53.3 & 9.3 & 44.0 \\
\hline & Hombres & 43.0 & 25.1 & 1.0 & 16.8 & 57.0 & & \\
\hline & Mujeres & 51.9 & 20.4 & 21.4 & 10.1 & 48.1 & & \\
\hline \multicolumn{9}{|l|}{ Chile } \\
\hline \multirow[t]{3}{*}{1990} & Total & 37.9 & 20.9 & 5.4 & 11.7 & 62.1 & 7.0 & 55.1 \\
\hline & Hombres & 33.5 & 21.3 & 0.2 & 12.0 & 66.5 & & \\
\hline & Mujeres & 45.9 & 20.1 & 14.7 & 11.1 & 54.1 & & \\
\hline \multirow[t]{3}{*}{1998} & Total & 37.5 & 18.5 & 5.1 & 13.9 & 62.5 & 7.2 & 55.3 \\
\hline & Hombres & 32.9 & 19.2 & 0.1 & 13.6 & 67.1 & & \\
\hline & Mujeres & 44.8 & 17.4 & 13.1 & 14.3 & 55.2 & & \\
\hline \multicolumn{9}{|c|}{ Colombia } \\
\hline 1990 & Total & 45.7 & 24.1 & 2.0 & 19.5 & 54.3 & 9.6 & 44.7 \\
\hline & Hombres & 45.1 & 22.6 & 0.1 & 22.3 & 54.9 & & \\
\hline & Mujeres & 46.6 & 26.3 & 5.0 & 15.2 & 53.4 & & \\
\hline 1998 & Total & 49.0 & 28.1 & 2.1 & 18.8 & 51.0 & 8.2 & 42.8 \\
\hline & Hombres & 49.2 & 28.4 & 0.2 & 20.7 & 50.8 & & \\
\hline & Mujeres & 48.8 & 27.7 & 4.7 & 16.4 & 51.2 & & \\
\hline Costa & & & & & & & & \\
\hline 1990 & Total & 41.2 & 18.9 & 5.8 & 16.4 & 58.8 & 22.0 & 36.8 \\
\hline & Hombres & 37.7 & 19.1 & 0.3 & 18.3 & 62.3 & & \\
\hline & Mujeres & 47.5 & 18.6 & 15.8 & 13.1 & 52.5 & & \\
\hline 1998 & Total & 45.4 & 17.5 & 6.0 & 21.9 & 54.6 & 17.0 & 37.6 \\
\hline & Hombres & 42.2 & 16.5 & 0.3 & 25.3 & 57.8 & & \\
\hline & Mujeres & 50.7 & 19.0 & 15.4 & 16.2 & 49.3 & & \\
\hline Ecuado & & & & & & & & \\
\hline 1990 & Total & 55.6 & 35.4 & 5.0 & 15.3 & 44.4 & 18.7 & 25.7 \\
\hline & Hombres & 51.7 & 32.6 & 0.7 & 18.4 & 48.3 & & \\
\hline & Mujeres & 62.1 & 39.9 & 12.1 & 10.1 & 37.9 & & \\
\hline 1998 & Total & 58.6 & 33.0 & 6.1 & 19.5 & 41.4 & 14.8 & 26.6 \\
\hline & Hombres & 54.5 & 28.9 & 1.0 & 24.6 & 45.5 & & \\
\hline & Mujeres & 64.1 & 46.7 & 9.4 & 8.0 & 35.9 & & \\
\hline Hondu & & & & & & & & \\
\hline 1990 & Total & 57.6 & 37.3 & 7.1 & 13.3 & 42.4 & 14.9 & 27.5 \\
\hline & Hombres & 45.1 & 25.7 & 0.5 & 18.9 & 54.9 & & \\
\hline & Mujeres & 72.0 & 50.5 & 14.6 & 6.9 & 28.0 & & \\
\hline 1998 & Total & 57.9 & 37.0 & 5.0 & 15.9 & 42.1 & 10.3 & 31.8 \\
\hline & Hombres & 52.0 & 27.9 & 0.9 & 23.2 & 48.0 & & \\
\hline & Mujeres & 64.1 & 46.7 & 9.4 & 8.0 & 35.9 & & \\
\hline
\end{tabular}


Cuadro 3 (continuación)

\begin{tabular}{|c|c|c|c|c|c|c|c|c|}
\hline \multirow{2}{*}{$\begin{array}{l}\text { País } \\
\text { y años }\end{array}$} & & \multicolumn{4}{|c|}{ Sector informal } & \multicolumn{3}{|c|}{ Sector formal } \\
\hline & & Total & $\begin{array}{c}\text { Trabajadores } \\
\text { por cuenta propia }\end{array}$ & $\begin{array}{l}\text { Servicio } \\
\text { doméstico }\end{array}$ & $\begin{array}{l}\text { Microem- } \\
\text { presas }^{b}\end{array}$ & $\overline{\text { Total }}$ & $\begin{array}{l}\text { Sector } \\
\text { público }\end{array}$ & $\begin{array}{c}\text { Empresas privadas } \\
\text { todas }^{\mathrm{c}}\end{array}$ \\
\hline \multicolumn{9}{|l|}{ México } \\
\hline \multirow{3}{*}{1990} & Total & 47.5 & 25.0 & 5.1 & 17.3 & 52.5 & 25.0 & 27.5 \\
\hline & Hombres & 46.6 & 25.1 & 0.8 & 20.7 & 53.4 & & \\
\hline & Mujeres & 48.8 & 24.6 & 13.4 & 10.8 & 51.2 & & \\
\hline \multirow[t]{3}{*}{1998} & Total & 49.6 & 24.9 & 4.8 & 19.8 & 50.4 & 21.7 & 28.7 \\
\hline & Hombres & 48.1 & 23.7 & 0.2 & 24.2 & 51.9 & & \\
\hline & Mujeres & 51.8 & 26.8 & 12.9 & 12.1 & 48.2 & & \\
\hline \multicolumn{9}{|c|}{ Panamá } \\
\hline \multirow[t]{3}{*}{1990} & Total & 36.0 & 19.8 & 7.9 & 8.3 & 64.0 & 32.0 & 32.0 \\
\hline & Hombres & 34.6 & 23.8 & 1.0 & 9.7 & 65.4 & & \\
\hline & Mujeres & 38.0 & 14.0 & 17.8 & 6.3 & 62.0 & & \\
\hline \multirow[t]{3}{*}{1998} & Total & 38.5 & 21.5 & 6.9 & 10.1 & 61.5 & 21.8 & 39.7 \\
\hline & Hombres & 35.9 & 22.8 & 1.3 & 11.9 & 64.1 & & \\
\hline & Mujeres & 42.3 & 19.5 & 15.4 & 7.4 & 57.7 & & \\
\hline \multicolumn{9}{|l|}{ Perúd $^{d}$} \\
\hline \multirow[t]{3}{*}{1990} & Total & 52.7 & 33.4 & 4.9 & 14.5 & 47.3 & 11.6 & 35.7 \\
\hline & Hombres & 46.3 & 28.9 & 0.6 & 16.9 & 53.7 & & \\
\hline & Mujeres & 62.9 & 40.4 & 11.6 & 10.8 & 37.1 & & \\
\hline \multirow[t]{3}{*}{1998} & Total & 53.7 & 30.2 & 5.5 & 18.0 & 46.3 & 7.2 & 39.1 \\
\hline & Hombres & 45.3 & 23.8 & 0.5 & 21.0 & 54.7 & & \\
\hline & Mujeres & 64.6 & 38.7 & 11.9 & 14.0 & 35.4 & & \\
\hline \multicolumn{9}{|c|}{ Uruguay $^{\mathrm{e}}$} \\
\hline \multirow{3}{*}{1990} & Total & 39.1 & 18.6 & 6.8 & 13.7 & 60.9 & 20.1 & 40.8 \\
\hline & Hombres & 33.7 & 18.6 & 0.2 & 15.0 & 66.3 & & \\
\hline & Mujeres & 46.6 & 18.5 & 16.2 & 11.8 & 53.4 & & \\
\hline \multirow[t]{3}{*}{1998} & Total & 41.2 & 20.1 & 7.5 & 13.6 & 58.8 & 16.8 & 42.0 \\
\hline & Hombres & 37.3 & 22.1 & 0.2 & 15.0 & 62.7 & & \\
\hline & Mujeres & 46.4 & 17.5 & 17.2 & 11.7 & 53.6 & & \\
\hline \multicolumn{9}{|c|}{ Venezuela } \\
\hline \multirow[t]{3}{*}{1990} & Total & 38.6 & 22.3 & 3.9 & 12.4 & 61.4 & 22.3 & 39.1 \\
\hline & Hombres & 38.3 & 22.0 & 0.4 & 15.9 & 61.7 & & \\
\hline & Mujeres & 39.3 & 22.8 & 10.4 & 6.1 & 60.7 & & \\
\hline \multirow[t]{3}{*}{1998} & Total & 43.0 & 28.9 & 4.7 & 9.4 & 57.0 & 19.0 & 38.0 \\
\hline & Hombres & 43.3 & 27.8 & 0.2 & 15.3 & 56.7 & & \\
\hline & Mujeres & 46.6 & 28.4 & 11.4 & 6.8 & 53.4 & & \\
\hline
\end{tabular}

Fuente: Estimaciones de la OIT, basadas en estudios de hogares por país y otras fuentes oficiales (series corregidas).

a Incluye trabajadores por cuenta propia (excepto profesionales y técnicos) y trabajadores familiares no remunerados.

b Empleados en establecimientos de hasta cinco trabajadores.

c Incluye empresas de seis o más trabajadores.

d Lima metropolitana.

e Montevideo.

presas cayó del $40 \%$ al 39\%, caída que se concentró principalmente en Brasil, Colombia y Venezuela. Más aún, si se excluyen las empresas pequeñas, la reducción alcanza a 2 puntos porcentuales (огт, 1998). Las empresas grandes (de más de 100 empleados) fueron las más afectadas por la apertura económica y la necesidad de aumentar la productividad (principalmente mediante reducción de empleo): sólo contribuyeron con 17 de cada 100 nuevos empleos creados en los años noventa. Además, el aumento de la flexibilidad laboral facilitó el ajuste, pero a costa de un nivel de empleo más irregular. Esto se aprecia claramente por la reducción de un $1 \%$ del empleo de las empresas grandes y medianas en 1998 en momentos en que ellas debían ajustarse a la creciente competencia de los productos asiáticos (gráfico 1).

La terciarización se refiere a la evolución del empleo desde los sectores productores de bienes hacia los servicios. La evolución fue rápida en países como Bolivia, Costa Rica, Ecuador, Perú y Uruguay, donde la participación del empleo en la manufactura cayó entre 4 y 6 puntos porcentuales en el decenio de 1990.

En otros países, el proceso fue más lento por efecto de la madurez alcanzada en su transformación pro- 
Hacia el sector terciario

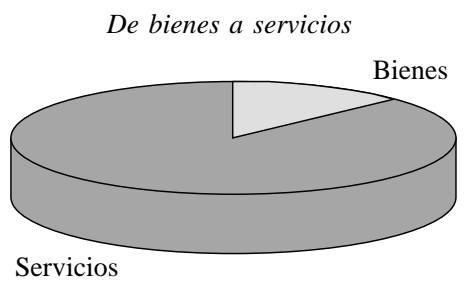

Informalización de servicios

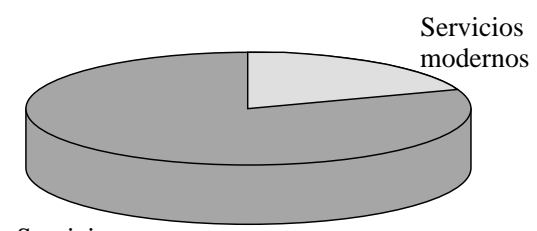

Servicios

informales
Hacia la informalidad

De moderno a informal

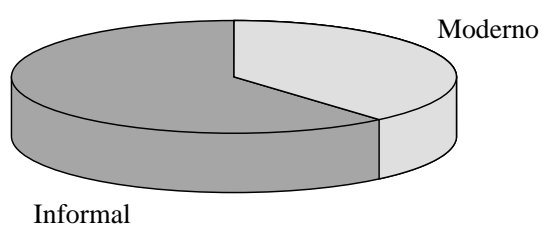

Modernización del sector informal

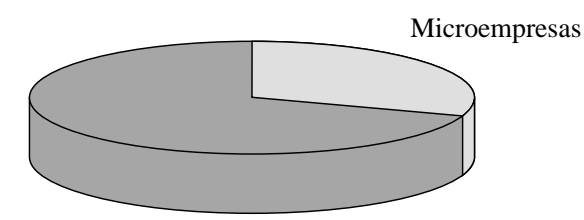

Otras actividades

informales ductiva (Chile), o por el sistema gradual adoptado (Colombia y Brasil) o, como en Panamá, por tratarse de una economía pequeña ya abierta.

En las nuevas condiciones estructurales a partir del ajuste, estos sectores son más vulnerables a cambios de la competencia. La industria manufacturera se contrajo en 1998 por la mayor competencia de los productos asiáticos. Esta contracción del producto y del empleo fue más intensa en las industrias elaboradoras de alimentos, textiles y vestuario, calzado, maquinaria $\mathrm{y}$ equipos.

El descenso del empleo en la manufactura y su aumento en los servicios es resultado, en parte, de la mayor competencia en una economía más abierta. La disminución del empleo coincidió con un aumento de la productividad, efecto que, sobre todo a corto plazo, sólo puede lograrse reduciendo el empleo. Este resultado se concentra principalmente en el sector urbano, ya que la agricultura, la pesca y la minería tienden a promover la expansión del empleo en los períodos de apertura.

La expansión del empleo en los sectores de servicios no puede interpretarse de antemano como un traslado a empleos de baja productividad. Algunos de los empleos que se generan en el sector forman parte de los procesos de modernización y globalización, como servicios de finanzas, comunicaciones y comer- cio. La productividad de estos sectores suele ser más alta que la de la manufactura y puede expandirse más rápidamente. Por desgracia, ésta no ha sido la situación de América Latina en el pasado reciente. Nueve de cada diez empleos nuevos que se crearon en los años noventa fueron de servicios, pero el $70 \%$ eran servicios de baja productividad, principalmente en el sector informal (servicios personales, comercio minorista y transporte). La terciarización en este contexto significa el deterioro de la calidad del empleo.

La informalización, es decir, el cambio de empleos formales a empleos informales, fue el tercer cambio importante en la estructura del empleo en el decenio de 1990. Como se mencionó, la limitada capacidad de la economía formal, pública y privada, para absorber trabajadores dejó a cantidades crecientes de personas sin más alternativa que crear sus propias ocupaciones en el sector informal. Dada la inexistencia de seguros de cesantía, el desempleo es un lujo que muy pocos pueden darse. El crecimiento lento e irregular, así como la expulsión de la fuerza de trabajo del sector público durante el ajuste atentaron contra la creación de empleos en actividades modernas.

Por consiguiente, el empleo informal se expandió del $44 \%$ al $48 \%$ entre 1990 y 1998. En esta categoría se incluyen el trabajo por cuenta propia, los empleados no remunerados de empresas familiares y las mi- 
croempresas (menos de 5 trabajadores). Sólo Argentina, Chile y Honduras lograron evitar que creciera el sector informal, en tanto que en los demás países el empleo informal crecía a un ritmo que duplicaba el del empleo no agrícola total.

Para la región en su conjunto, 61 de cada 100 empleos generados en los años noventa fueron informales. La gran mayoría de los empleos en servicios fueron informales; además, el componente más dinámico del crecimiento del empleo informal ha sido la ocupación de la microempresa. De cada 10 nuevos empleos, las microempresas contribuyeron con más de tres (gráfico 1). Esto podría sugerir un cambio positivo en el empleo informal, ya que las microempresas están más organizadas que la mayoría de las actividades informales y sus ingresos medios son más elevados que los del resto del sector informal (aunque no tan altos como los del sector formal). Por lo general, el ingreso medio en las microempresas se acerca al 90\% del ingreso medio de las actividades modernas, pero sólo al 55\% del ingreso medio en las empresas medianas y grandes.

Las microempresas están convirtiéndose cada vez más en opciones válidas de empleo, atribuyéndoseles todos los nuevos empleos creados en 1998. Sin embargo, el asunto merece un análisis más a fondo ya que, siendo mejores los ingresos, dejan mucho que desear las condiciones de trabajo, la estabilidad laboral y la protección social. Entre el $65 \%$ y el $95 \%$ de los que trabajan en microempresas carecen de un contrato de trabajo escrito, y entre $65 \%$ y $80 \%$ no tienen ni seguro médico ni previsión. Tienden a trabajar más horas y tienen más accidentes del trabajo. También son más frecuentes las violaciones de los derechos laborales básicos (trabajo infantil, libertad de asociación, negociación colectiva y trabajo forzado) en este tamaño de establecimientos que en los más grandes. Por supuesto que la precariedad no es característica privativa de la pequeña empresa, ya que se da también en las empresas medianas y grandes (orT, 1995).

La precarización se refiere a la creciente precariedad del trabajo, como consecuencia del aumento de la competitividad en un ambiente laboral más flexible. La búsqueda de reducciones de costos y su flexibilización para promover el mejoramiento de la competitividad ha llevado a reformas de la legislación laboral que han introducido la flexibilidad en el margen. Se introdujeron contratos "atípicos" para las nuevas contrataciones como alternativa de menor costo y más flexible que el contrato de duración ilimitada que antes prevalecía en las relaciones laborales. Con la ma- yor flexibilidad y los menores costos de mano de obra se esperaba crear un mayor número de empleos asalariados.

En realidad, en los años noventa el empleo asalariado creció con más rapidez que el empleo total, lo que sugiere que la reforma dio incentivos para la contratación. Sin embargo, el costo social fue la creciente precariedad del trabajo. La introducción de contratos "atípicos" estuvo acompañada de un aumento del número de trabajadores sin contrato de trabajo escrito. Cabe recordar que ni los contratos atípicos ni la falta de contratos escritos suponen una protección laboral inferior a la del contrato típico. Sólo en Argentina, la reforma permitió rebajas en los contratos temporales y que la existencia de una relación laboral deba probarse, en ausencia de un contrato escrito. Sin embargo, la inspección y el control se hacen más difíciles en los contrato temporales. En el caso de trabajadores sin contrato, muchos son clandestinos que reciben pagos en efectivo y sus condiciones de empleo son casi imposibles de verificar. Esta situación se da en condiciones en que la inspección laboral es por lo general débil y, debido a la reforma, ha debilitado su orientación al reconocer que el contrato típico es rígido.

En Chile, un 30\% de los trabajadores no tenía contrato o tenía contratos atípicos, $40 \%$ en Argentina y Colombia y $74 \%$ en Perú (cuadro 4). La mayoría se hallaba en microempresas: $50 \%$ en Chile, $65-70 \%$ en Colombia y Argentina y $80 \%$ en Perú. Con todo, las empresas medianas y grandes registraban la mayor proporción de contratos atípicos y tenían porcentajes significativos de trabajadores sin contrato: 6\% en Chile, $11 \%$ en Perú y $32 \%$ en Argentina y Colombia. En el caso de las microempresas, hay una clara superposición de la informalidad y la precariedad, ya que ambas son resultado de la incapacidad de pagar el costo de la protección laboral. En empresas de mayor tamaño, la cantidad de trabajadores no registrados es indicio de evasión legal (Tokman y Martínez, eds., 1999).

La proporción de trabajadores, potenciales o reales, sujetos a precariedad no es sólo elevada sino que equivale a toda la expansión del empleo en el decenio de 1990 en la mayoría de los países. De cuatro países analizados, sólo en Colombia hubo un aumento del empleo de duración indefinida; en Chile, Argentina y Perú, este tipo de contratos se redujo en términos absolutos. La transición del empleo permanente al empleo temporal fue distinta en cada país. En Argentina, la caída de los contratos de duración indefinida coincidió con el aumento de trabajadores sin contrato, principalmente en las empresas de mayor tamaño. En Perú, 
Argentina, Chile, Colombia y Perú: Empleos precarios

\begin{tabular}{|c|c|c|c|c|c|c|c|c|c|c|}
\hline & \multicolumn{3}{|c|}{ Trabajadores asalariados $^{\mathrm{a}}$} & \multicolumn{3}{|c|}{ Costo mano de obra por horab } & \multicolumn{4}{|c|}{ Composición del cambio en el empleo asalariado ${ }^{c}$} \\
\hline & $\begin{array}{c}\text { Con } \\
\text { contratos } \\
\text { temporales }\end{array}$ & $\begin{array}{c}\text { Sin } \\
\text { contratos }\end{array}$ & Total & $\begin{array}{c}\text { Con } \\
\text { contratos } \\
\text { temporales }\end{array}$ & $\begin{array}{c}\text { Sin } \\
\text { contratos }\end{array}$ & $\begin{array}{l}\text { Duración } \\
\text { indefinida }\end{array}$ & $\begin{array}{l}\text { Duración } \\
\text { indefinida }\end{array}$ & Temporal & $\begin{array}{c}\text { Sin } \\
\text { contratos }\end{array}$ & $\begin{array}{c}\text { Cambio total } \\
\text { en empleo } \\
\text { asalariado }\end{array}$ \\
\hline Argentina & 12.7 & 33.0 & 35.7 & 3.5 & 2.8 & 6.1 & -652.7 & 25.7 & 726.9 & 100.0 \\
\hline Chile & 14.7 & 15.6 & 30.3 & 1.4 & 1.0 & 2.1 & -89.9 & 138.9 & 51.0 & 100.0 \\
\hline Colombia & 8.3 & 31.0 & 39.3 & 1.9 & 1.6 & 3.3 & 81.9 & 13.3 & 4.8 & 100.0 \\
\hline Perú & 32.6 & 41.1 & 73.7 & 1.4 & 1.1 & 2.1 & -19.3 & 56.8 & 62.6 & 100.0 \\
\hline
\end{tabular}

Fuente: Tokman y Martínez (eds.) (1999) y OIT (1998).

a Porcentajes del empleo asalariado total.

b En dólares.

c Porcentaje de los cambios en el empleo asalariado entre 1990 y 1996.

la pérdida de empleo de plazo indefinido la constituyeron por mitades trabajadores con contrato temporal $\mathrm{y}$ trabajadores sin contrato, principalmente en microempresas. En Chile, la mayoría de los empleos nuevos en las empresas más grandes fueron con contratos temporales.

Los cuatro procesos descritos se tradujeron en deterioro de la calidad de la protección laboral en el decenio de 1990. La privatización, un cambio potencialmente positivo, no lo fue porque hubo insuficiente creación de nuevos empleos en las empresas privadas modernas. La terciarización es también neutral a priori, ya que los buenos empleos en servicios debieron compensar la menor disponibilidad de empleos en la manufactura. Sin embargo, la mayor parte de los nuevos empleos en servicios era de baja productividad. La informalización y la precarización deterioraron claramente la calidad del empleo, sólo contrarrestado de alguna manera por la rápida expansión del empleo en las microempresas.

Los cambios en la estructura del empleo pueden apreciarse con mayor claridad en una perspectiva de más largo plazo. Como se advierte en el gráfico $2,{ }^{2}$ durante las tres décadas previas al ajuste (1950-1980) en promedio, en América Latina, el 60\% de los nuevos empleos fueron creados por los sectores formales de la economía, siendo el gobierno responsable del

\footnotetext{
${ }^{2}$ Nótese que el gráfico 2 está basado en una definición del sector informal en que, en algunos países, la microempresa incluye hasta 10 trabajadores, por disponibilidad de información, y que su participación está relacionada con al empleo urbano. Las series corregidas cuando las microempresas del sector informal incluyen hasta cinco trabajadores y se relacionan con el empleo urbano no permiten una comparación de largo plazo.
}

$15 \%$ y las empresas privadas medianas y grandes del $45 \%$ restante. El sector informal contribuyó con el $40 \%$ de los nuevos empleos, de los cuales, sólo el 10\% correspondía a microempresas (OIT, 1996).

Un cambio radical en la estructura ocurrió durante la década de ajuste de 1980. La contribución del empleo moderno disminuyó a 2 de cada diez empleos, reducción que se concentró en las empresas privadas modernas que tuvieron que ajustarse a una economía más abierta. El sector informal actuó de amortiguador al doblar su contribución a la creación de empleos, principalmente en microempresas, las que crecieron a más del triple. El decenio de 1990 muestra una recuperación en la absorción de empleo por las empresas privadas de mayor tamaño y una continua expansión del empleo informal.

En suma, la privatización ha significado que el empleo público ya no contribuye a absorber mano de obra. Las empresas más grandes, aunque recuperándose

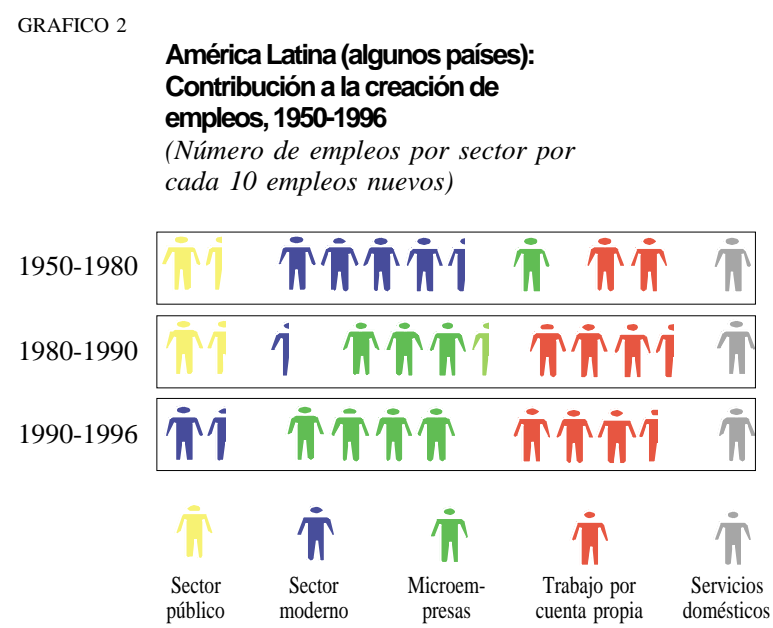


desde la década del ajuste, todavía están muy por debajo de su nivel anterior, y es probable que no sean capaces de alcanzarlo, dado el cambio tecnológico y la descentralización de la producción y del empleo. De esta forma las empresas independientemente de su tamaño contribuyen con los mismos 5.5 de cada 10 nuevos empleos, tal como en el período previo al ajuste. La diferencia es ahora que los contribuyentes principales son las microempresas (incluidas las pequeñas). Como en este sector la informalidad y la precariedad todavía prevalecen, el cambio en el empleo se ha traducido en un deterioro de la calidad.

\section{d) Tendencias de los salarios y diferencias salaria- les}

Durante el período de ajuste se esperaban dos efectos sobre los salarios. Sus niveles debían tender a subir con la expansión de la productividad, y las diferencias de salario por niveles de capacitación debían disminuir, a medida que aumentaba la demanda de mano de obra no calificada por efecto de la expansión del comercio basada en los sectores que hacen uso intensivo de mano de obra.

En 1990 los niveles reales del salario industrial y el salario mínimo estaban por debajo de los de 1980. En ambos casos hubo una recuperación en el decenio de 1990, gracias principalmente al éxito en reducir la inflación, que bajó de tres dígitos a menos del 10\% en promedio en toda América Latina. También coadyuvó la elevación de la productividad en el último período, sobre todo en el sector industrial. Sin embargo, como se aprecia en el cuadro 2, los salarios mínimos están todavía muy por debajo de los de 1980.

Las diferencias de salario se han comportado de una forma inesperada. Han tendido a aumentar las diferencias entre salarios mínimos y salarios industriales y aquellos por niveles educativos o de especialización. Los salarios industriales crecieron a un ritmo de $1.4 \%$ anual entre 1990 y 1997, mientras los salarios mínimos sólo lo hacían en un $0.3 \%$. En América Latina las diferencias de ingreso entre los profesionales y técnicos y los trabajadores de los sectores de baja productividad aumentaron en promedio de $40 \%$ a $60 \%$ entre 1990 y 1994. Esto se debió a una expansión significativa de los ingresos reales de los trabajadores muy especializados en las actividades modernas, y a un lento crecimiento, y hasta reducción, de los salarios de la mano de obra no calificada en los sectores de baja productividad. En 8 de los 10 países sobre los que se dispuso de información, aumentó la diferencia de salarios según niveles de capacitación (CEPAL, 1997a) y lo propio sucedió al comparar el salario de trabajadores calificados y no calificados desde 1988 (BID, 1998).

Mientras las diferencias de salarios aumentaron en América Latina en este período, en los países del sudeste asiático la tendencia fue exactamente la contraria. En 1980, esas diferencias eran en América Latina las más altas del mundo, y hacia 1997 llegaban a 1.9 veces la de los países desarrollados y del sudeste asiático.

Varias son las explicaciones posibles de este comportamiento anómalo: el efecto de la liberalización de capitales en los precios de los bienes de capital que pudo haber promovido un aumento de la inversión y una demanda complementaria de mano de obra calificada; la expansión de las importaciones de países como China, que tienen más abundancia aún de mano de obra no calificada que América Latina; y la apreciación del tipo de cambio que favoreció el aumento de bienes no transables que hacen uso relativamente más intensivo de mano de obra calificada (Lustig, 1998).

Por otro lado, estudios realizados sobre Brasil, Chile y Perú (Meller y Tokman, 1996; Paes de Barros y otros, 1996; Saavedra, 1996) sugieren que el grado de madurez y la naturaleza del proceso de apertura comercial influyen en la evolución de las diferencias de salarios. En Chile, con un proceso de apertura más maduro, las empresas grandes pudieron expandir el empleo después de 1984; en Brasil y Perú (dos países en que el proceso comenzó tardíamente), disminuyó el empleo en las empresas grandes para aumentar la productividad y la competitividad, concentrándose la absorción laboral en las empresas pequeñas y las microempresas. En el primer caso hubo un aumento de la demanda de mano de obra calificada, mientras que en los otros dos hubo un traslado del empleo de las empresas y sectores de alta productividad a los de baja productividad. En Perú esto fue acompañado por una expansión neta del empleo, pero en Brasil hubo contracción. En ambos casos, no obstante, los salarios de la mano de obra no calificada disminuyeron, ya sea por el cambio ocupacional o por la introducción de relaciones laborales menos protegidas. Los trabajadores de la microempresa ganan en promedio $30 \%$ a $50 \%$ menos que los de empresas más grandes (orT, 1997a) y $20 \%$ incluso cuando se homogeneizan las características personales (BID, 1998). Por otro lado, las grandes empresas que reemplazan trabajadores con contratos de largo plazo por trabajadores temporales reducen los salarios entre $35 \%$ y $40 \%$ o en $15 \%$ a $30 \%$ más si no se firma un contrato por escrito (cuadro 4). Esta precarización del contrato de trabajo se aplica princi- 
palmente a los trabajadores no calificados y neutraliza cualquier efecto de demanda que pudiera originarse como consecuencia de la apertura comercial. (огт, 1998).

\section{e) La pobreza y la equidad}

La pobreza y la desigualdad han aumentado durante el proceso de reforma. En promedio, hoy hay más población pobre y las diferencias de ingreso son más grandes que antes en América Latina. La tendencia no ha sido continua. En los años noventa, cuando varios países habían cumplido ya las fases de estabilización y apertura, la pobreza disminuyó en la mayoría de los países que disponen de información. Sólo Argentina y Venezuela registraron un aumento del nivel de pobreza, y en México permaneció constante; pero los 13 países con información disponible muestran una reducción (CEPAL, 1999).

El nivel de pobreza actual es todavía más grande que el de 1980 y no ha sido compensado con un aumento de la equidad. Por el contrario, la concentración del ingreso ha aumentado significativamente desde principios de los años ochenta y alcanza en la actualidad un coeficiente de Gini similar al que existía en 1970 (0.52). Esto se debe al descenso de la participación en el ingreso del quintil más pobre y al aumento continuo del quintil superior, sólo interrumpido entre 1980 y 1983. Los quintiles intermedios, aunque en mejor situación que el más pobre, todavía no recuperan su participación en el ingreso de principios del decenio de 1980. De hecho, de los dos países (Chile y Uruguay) que muestran una disminución importante de la pobreza, sólo Uruguay fue capaz simultáneamente de registrar un mejoramiento de la equidad.

La concentración del ingreso en América Latina ha sido históricamente la más alta del mundo. Hoy, la participación en el ingreso del 5\% más alto duplica la del mismo grupo en los países industrializados, y supera en más de un $60 \%$ la de los países del sudeste asiático. En el otro extremo, el $30 \%$ más pobre registra la participación en el ingreso más baja del mundo, que con el $7.5 \%$ es apenas el $60 \%$ del nivel que alcanza el mismo grupo en los países industrializados y de Asia (BID, 1998). A mayor abundamiento, cuando se compara un país que ha tenido éxito, como Chile, con los Estados Unidos, puede observarse que las participaciones en el ingreso del $20 \%$ más pobre son similares (alrededor del 4.5\%); sin embargo, para encontrar una participación comparable del $20 \%$ más rico es necesario remontarse a 1929. Si se estima el coeficiente de Gini para el 90\% de la población de América Lati- na (excluyendo al 10\% más rico) su promedio sería de 0.36, similar al de los Estados Unidos, y en seis países sería hasta menor (BID, 1998). Esto indica claramente que la mayor concentración del ingreso por los grupos más ricos es un factor explicativo fundamental.

Igualmente importante es analizar por qué la globalización y el conjunto de medidas de ajuste que la acompañó no contribuyeron a que América Latina alcanzara niveles de equidad cercanos a los del resto del mundo. El sentido común, basándose en los estudios pioneros de Kuznets, llevaría a esperar que, después de un período de aumento de la concentración en la etapa inicial del desarrollo, la equidad aumentaría. Este sentido común no parece sostenerse hoy, ni siquiera en los países desarrollados. La tendencia a una mayor equidad se ha interrumpido o, en el mejor de los casos, permanecido estable. La desigualdad ha aumentado en los Estados Unidos desde fines de los años sesenta; en el Reino Unido subió entre 1979 y 1989, y lo mismo ocurrió en Suecia a partir de 1988 (Atkinson, 1996, y Krugman, 1995). Esto sugiere que los países de América Latina pueden estar siguiendo una evolución universal, producto de la homogeneización de las políticas, saltándose la etapa de aumento de la equidad que se registró anteriormente en esos países.

Diversos factores podrían ayudar a explicar por qué la globalización no ha mejorado la equidad en América Latina. Se relacionan con la dinámica de la población, la distribución de las oportunidades y el funcionamiento de los mercados de trabajo durante los procesos de ajuste.

El acelerado crecimiento de la población se ha traducido, particularmente en los hogares pobres, en un mayor tamaño (en el quintil más pobre, un 50\% de más miembros que en el más rico), tasas de dependencia más elevadas (casi el triple) y menores tasas de participación (60\%) (CEPAL, 1997a).

El acceso a las oportunidades, en especial a la enseñanza, es también desigual. En promedio, los años de instrucción han aumentado (aunque más lentamente que en los países del sudeste asiático), pero tienden a distribuirse inequitativamente. Hay una alta tasa de deserción escolar en los hogares pobres. El 94\% de los niños pobres en los países con alto desarrollo educativo se matricula en los primeros años de la escuela, contra el $76 \%$ en los países menos avanzados. Las tasas de matrícula disminuyen respectivamente al $63 \%$ y al $32 \%$ en el quinto año, y al $15 \%$ y el $6 \%$ en el noveno año. Las tasas de ingreso son similares entre niños pobres y los de las familias de mayores recursos, pero los últimos permanecen en la escuela por períodos más 
largos. Al quinto año, las tasas eran $93 \%$ y $83 \%$, en tanto que al noveno, eran de $58 \%$ y $49 \%$ respectivamente (BID, 1998). El acceso desigual se refuerza por la mayor proporción de miembros que entran a la universidad entre las familias de ingresos más altos y por diferencias de calidad de la educación. El rendimiento escolar (matemáticas y ciencias) en las escuelas privadas, a las que asisten sólo niños de familias de altos ingresos, es, en promedio, $50 \%$ más elevado que el que alcanzan las escuelas públicas, a las que asiste el $90 \%$ de los niños pobres.

Una parte significativa de las diferencias de ingresos -más del 55\% - la explican los resultados del mercado de trabajo. Como se argumentó, el aumento del desempleo, los desplazamientos hacia empleos menos productivos y más inestables y el aumento de las diferencias de salarios tienden a elevar las desigualdades de ingreso porque afectan sesgadamente a los hogares pobres. Las tasas de desempleo son más altas en los hogares pobres (en Chile, en 1996, la tasa del quintil más pobre era 2.7 veces la del quintil más rico). Además, la asignación de empleos es segmentada. Los empleos de buena calidad y remuneración son mayoritariamente ocupados por miembros de familias de altos ingresos, en tanto que los empleos de baja calidad, informales y de baja calificación los cubren los provenientes de hogares pobres. En Chile, el $40 \%$ más pobre registró un aumento del desempleo entre 1992 y 1994; mientras la ocupación formal disminuía, el empleo informal crecía en más de $20 \%$. Lo contrario sucedió en el quintil más alto, que expandió el empleo formal en $13.5 \%$, y disminuyó el informal en $2.7 \%$. Más de la mitad de los nuevos empleos que requieren altos niveles educativos fue ocupada por miembros de familias de altos ingresos, mientras que el $40 \%$ más pobre registraba escasa movilidad ascendente y ocupaba empleos que exigían educación secundaria o técnica (Tokman, 1998).

El funcionamiento del mercado del trabajo es determinante en la evolución de la pobreza y la equidad. Esto no quiere decir que otros ingresos carezcan de importancia, sino que ambos no son independientes. En la actualidad, la concentración del ingreso por hogares y la concentración de los ingresos del trabajo de 14 países de América Latina son similares, con coeficientes de Gini de 0.52 y 0.51 respectivamente (BID, 1998). Este análisis puede trasladarse a la pobreza y a la equidad. Lo hicimos para nueve países en la década de 1990 (cuadros 5 y 6): Argentina, Brasil, Colombia, Costa Rica, Chile, México, Panamá, Perú y Venezuela (огт, 1997a).
En promedio, para los nueve países, tanto el empleo como el ingreso por trabajador aumentaron en los años noventa, pero la distribución del ingreso favoreció a las familias del $20 \%$ superior. El empleo creció más rápidamente en los hogares pobres, seguido por los hogares del $20 \%$ más rico. Los grupos de ingresos medios fueron los menos favorecidos (gráfico 3). El ingreso medio, sin embargo, se elevó con rapidez mayor en el grupo de ingresos más altos, algo

GRAFICO 3

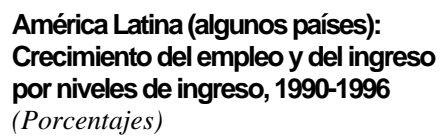

Empleo

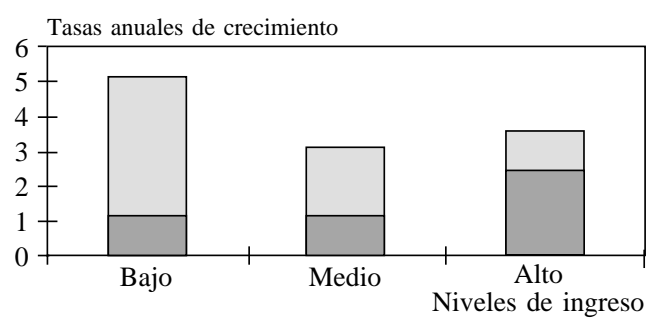

$\square$ Sector moderno $\square$ Sector informal

Ingreso real medio

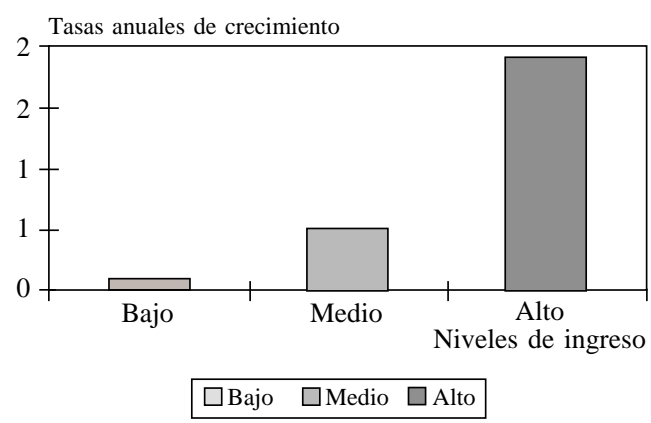

Distribución del ingreso de los ocupados

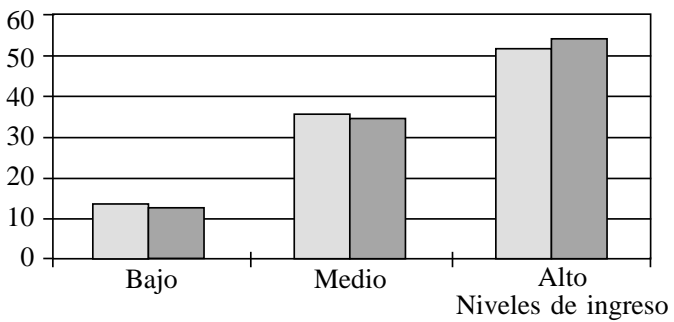

$\square 1990 \quad \square 1996$ 
América Latina (nueve países): Indicadores de transformación del empleo, informalidad y crecimiento del ingreso medio por grupos de ingreso a

(Porcentajes y tasas de crecimiento anual)

\begin{tabular}{|c|c|c|c|c|c|c|c|c|c|c|c|c|c|}
\hline \multirow[t]{2}{*}{ País } & \multirow[t]{2}{*}{ Período } & \multicolumn{4}{|c|}{ Empleo $^{\text {b }}$} & \multicolumn{4}{|c|}{ Informalidad $^{\mathrm{c}}$} & \multicolumn{4}{|c|}{$\begin{array}{l}\text { Ingreso promedio } \\
\text { de los ocupados }\end{array}$} \\
\hline & & Total & Bajo & Mediano & Alto & Total & Bajo & Mediano & Alto & Total & Bajo & Mediano & Alto \\
\hline Argentina & (1990-1996) & 0.5 & 1.0 & 1.2 & -1.3 & 66 & 79 & 77 & $\ldots$ & 4.5 & 3.5 & 4.2 & 6.4 \\
\hline Brasil & $(1992-1995)$ & 3.5 & 5.8 & 2.2 & 3.5 & 81 & 66 & 85 & 95 & 1.3 & 1.3 & 1.2 & 1.5 \\
\hline Chile & $(1990-1996)$ & 3.1 & 3.8 & 2.7 & 2.9 & 29 & 14 & 30 & 42 & 5.6 & 4.1 & 5.8 & 5.9 \\
\hline Colombia & $(1992-1996)$ & 1.8 & 1.2 & 1.9 & 2.6 & 37 & $\ldots$ & 66 & 22 & 3.6 & 2.5 & 3.3 & 3.9 \\
\hline Costa Rica & $(1990-1995)$ & 4.4 & 3.7 & 3.5 & 7.0 & 51 & 70 & 48 & 42 & 1.9 & -0.6 & 1.4 & 2.7 \\
\hline México & $(1990-1995)$ & 6.4 & 7.8 & 6.0 & 5.5 & 58 & 87 & 54 & 18 & -2.1 & -3.8 & -2.1 & 0.2 \\
\hline Panamá & (1989-1995) & 6.8 & 6.3 & 7.2 & 6.8 & 38 & 45 & 35 & 31 & 1.4 & 2.6 & 0.6 & 2.2 \\
\hline Perú & (1991-1995) & 5.1 & 6.3 & 4.2 & 5.4 & 69 & 97 & 51 & 32 & 3.0 & 2.7 & -0.2 & 3.0 \\
\hline Venezuela & (1990-1996) & 2.6 & 2.3 & 2.2 & 3.8 & 77 & 100 & 87 & 31 & -10.3 & -11.5 & -9.8 & -9.1 \\
\hline
\end{tabular}

Fuente: OIT, basado en estudios de hogares en Argentina (Gran Buenos Aires), Brasil (zona urbana), Chile (zona urbana), Colombia (10 zonas metropolitanas), Costa Rica (zona urbana), México (39 ciudades), Panamá (zona metropolitana), Perú (Lima metropolitana) y Venezuela (zona urbana).

a Información sobre ocupados en zonas urbanas, excluidos los sectores agrícola y minero. Se agrupó a los trabajadores de acuerdo con los niveles de ingreso determinados por quintiles de ingreso per cápita de hogares. Los niveles de ingreso corresponden a: bajo (quintil I + quintil II), medio (quintil III + quintil IV) y alto (quintil V). Todos los indicadores se refieren al período indicado para cada país.

b Tasa de crecimiento anual del empleo (promedio del período indicado para cada país).

c Porcentaje de empleos nuevos en actividades informales durante el período considerado para cada país.

d Tasa de crecimiento anual del ingreso medio de los ocupados, medida a precios constantes (promedio del período anotado para cada país).

más lentamente en los grupos medios y con suma lentitud en el grupo de hogares más pobres. Esto es resultado del acceso segmentado al empleo por diferentes grupos de ingreso. Los pobres, con escaso capital humano, tienden a ingresar a empleos informales, mientras que las familias de ingresos altos tienden a acceder a ocupaciones mejores. Cerca de 70 de cada cien nuevos empleos llenados por el $40 \%$ de los más pobres eran del tipo informal, mientras que en el caso del $40 \%$ de ingresos medios, la tasa llegó al 52\%. Como resultado, la concentración del ingreso, medida como la diferencia de ingreso entre el $10 \%$ más rico y el $40 \%$ más pobre, aumentó en todos los países estudiados. Tanto los pobres como los grupos medios disminuyeron su participación en el ingreso total, y sólo el 20\% más rico la aumentó. La pobreza relativa, sin embargo, probablemente decreció. La expansión del empleo y el ingreso por trabajador, además del aumento del número de trabajadores por familia, se tradujo en un ingreso más elevado para los pobres y en una reduc- ción de la pobreza en la mayoría de los países durante el período considerado, salvo en México y Venezuela.

La situación es bastante homogénea entre los países. En todos ellos, los ingresos por trabajador crecieron más rápidamente en el grupo de ingresos más elevados, y el empleo lo hizo en seis de los nueve considerados. La situación se hace más heterogénea en relación con los grupos pobres y medios. El empleo creció más rápidamente entre el $40 \%$ más pobre que en el $40 \%$ de ingresos medios, en la mayoría de los países. Sin embargo, el ingreso por trabajador creció más aceleradamente en el grupo de ingresos medios que en el grupo de ingresos bajos en seis de los nueve países analizados. Como se señaló anteriormente, esa evolución se debe al acceso diferenciado al empleo. Las diferencias de ingresos entre el $20 \%$ más rico y el $40 \%$ más pobre aumentaron en todos los casos, soportando el costo los grupos medio y pobre. En la mitad de los países los pobres perdieron más terreno que la clase media, mientras en los restantes fue al revés. 
CUADRO 6

América Latina (nueve países): Distribución del ingreso de los ocupados por nivel de ingreso

(Porcentajes)

\begin{tabular}{|c|c|c|c|c|}
\hline \multirow[t]{2}{*}{ País } & \multicolumn{3}{|c|}{ Niveles } & \multirow[t]{2}{*}{ Cociente de desigualdad } \\
\hline & Bajo & Medio & Alto & \\
\hline \multicolumn{5}{|l|}{ Argentina } \\
\hline 1990 & 7.9 & 34.6 & 57.5 & 7.0 \\
\hline 1996 & 6.8 & 35.4 & 57.8 & 8.0 \\
\hline Variación & -1.1 & 0.8 & 0.3 & \\
\hline \multicolumn{5}{|l|}{ Brasil } \\
\hline 1992 & 5.1 & 29.2 & 65.7 & 19.2 \\
\hline 1995 & 5.3 & 27.3 & 67.4 & 21.5 \\
\hline Variación & 0.2 & -1.9 & 1.7 & \\
\hline \multicolumn{5}{|l|}{ Chile } \\
\hline 1990 & 11.3 & 30.7 & 58.0 & 9.4 \\
\hline 1996 & 10.8 & 30.6 & 58.6 & 10.4 \\
\hline Variación & -0.5 & -0.1 & 0.6 & \\
\hline \multicolumn{5}{|l|}{ Colombia } \\
\hline 1992 & 16.8 & 33.5 & 49.7 & 4.3 \\
\hline 1996 & 15.6 & 33.0 & 51.4 & 4.6 \\
\hline Variación & -1.2 & -0.5 & 1.7 & \\
\hline \multicolumn{5}{|l|}{ Costa Rica } \\
\hline 1990 & 19.2 & 41.6 & 39.2 & 3.0 \\
\hline 1995 & 15.8 & 38.7 & 45.5 & 3.4 \\
\hline Variación & -3.4 & -2.9 & 6.3 & \\
\hline \multicolumn{5}{|l|}{ México } \\
\hline 1990 & 15.0 & 37.5 & 47.5 & 6.0 \\
\hline 1995 & 14.3 & 35.9 & 49.8 & 7.1 \\
\hline Variación & -0.7 & -1.6 & 2.3 & \\
\hline \multicolumn{5}{|l|}{ Panamá } \\
\hline 1989 & 14.3 & 37.7 & 48.0 & 4.7 \\
\hline 1995 & 14.7 & 35.9 & 49.4 & 4.7 \\
\hline Variación & 0.4 & -1.8 & 1.4 & \\
\hline \multicolumn{5}{|l|}{ Perú } \\
\hline 1991 & 13.2 & 34.7 & 52.1 & 7.9 \\
\hline 1995 & 14.2 & 30.9 & 54.9 & 8.5 \\
\hline Variación & 1.0 & -3.8 & 2.8 & \\
\hline \multicolumn{5}{|l|}{ Venezuela } \\
\hline 1990 & 18.4 & 38.5 & 43.1 & 4.7 \\
\hline 1996 & 13.6 & 39.0 & 47.4 & 7.6 \\
\hline Variación & -4.8 & 0.5 & 4.3 & \\
\hline
\end{tabular}

Fuente: Datos de la OIT, basados en estudios de hogares en Argentina (Gran Buenos Aires), Brasil (zona urbana), Chile (zona urbana), Colombia (10 zonas metropolitanas), Costa Rica (zona urbana), México (39 ciudades), Panamá (zona metropolitana), Perú (Lima metropolitana) y Venezuela (zona urbana).

a Precios constantes.

b El cociente de desigualdad mide la relación entre el ingreso medio nominal del quintil más alto (quintil V) y el que corresponde a ingresos bajos (quintiles I y II). 


\section{III}

\section{Ajuste, economías globales y estratificación social}

Los procesos de ajuste de las economías nacionales y la subsiguiente integración económica al mundo internacional han tenido un impacto significativo en el sistema de estratificación social. Ello se debe a que el sistema se basa principalmente en la estructura ocupacional, la que, a su vez, ha cambiado, en la medida en que el mercado de trabajo se ha transformado por la reestructuración económica. Algunos de estos cambios y sus consecuencias sociológicas se analizan en adelante. Particularmente, analizaremos cuatro procesos de cambio. El primero es la relación entre la transformación del empleo público y el empobrecimiento de la clase media. El segundo es la forma en que la privatización genera una mayor heterogeneidad social, como resultado tanto de una movilidad laboral involuntaria como del incremento de la subcontratación. El tercero es la influencia de la transnacionalización en los sistemas de relaciones laborales. Por último, veremos la creciente diferenciación que surge en las áreas ocupacionales que se expanden, como las microempresas y la agricultura.

\section{El empleo público y la clase media}

El primer problema importante en este ámbito tiene relación con el nuevo papel del Estado y su impacto sobre el mercado del trabajo. Su transformación ha tenido dos efectos principales. En primer lugar, en casi todos los países de la región el empleo público ha disminuido. En promedio, como proporción de la población económicamente activa, el empleo público disminuyó del $16 \%$ de principios de los años ochenta al 13\% hoy, es decir, bajó aproximadamente $20 \%$. Este promedio encubre caídas muy pronunciadas en algunos países: por ejemplo, entre 1990 y 1997, el empleo público cayó 32\% en Argentina, 33\% en Bolivia, 22\% en Costa Rica y $28 \%$ en Panamá. Este proceso tuvo una influencia importante en la estratificación social de América Latina. Es un hecho comprobado que los orígenes y el desarrollo de la clase media en la región estaban estrechamente vinculados con el papel del Estado en la promoción del desarrollo social y económico durante el siglo XX. Mientras en algunos países el proceso comenzó en los primeros decenios, en otros tuvo lugar después de la segunda guerra mundial y en algunos está todavía vigente; pero ha sido generalizado. Significó la creación de empleo público y la contratación de funcionarios públicos para ejecutar las políticas de desarrollo del Estado en los sectores de salud, educación, obras públicas y vivienda. El Estado promovió la creación de empleos en empresas públicas de diferentes tipos, pero esencialmente en los sectores que consideraba de importancia estratégica nacional (servicios públicos, principales recursos naturales e industrias básicas). Un ejemplo de la importancia del empleo público para el desarrollo de la clase media es la observación (Echeverría, 1985) de que, durante la década de 1970 , el $60 \%$ de todos los profesionales latinoamericanos eran funcionarios públicos.

No es clara la situación ocupacional de los empleados públicos que perdieron su empleo como resultado de la reducción de la administración pública, y probablemente sea distinta de un país a otro. En algunos casos los antiguos funcionarios cobraron desahucios que les permitieron comenzar sus propias empresas, generalmente como contratistas independientes o microempresarios. En muchos casos pueden haber mejorado su condición. En otros casos, los despidos se tradujeron en una movilidad descendente. En efecto, en algunos países, funcionarios despedidos de la administración pública y de las empresas del Estado sufrieron un proceso de empobrecimiento y de pérdida de condición social, sobre todo cuando no eran profesionales y basaban su status, no en el nivel educacional, sino en posiciones ocupacionales que habían logrado.

De la misma forma, los que se quedaron en la administración pública también descendieron de condición, al decaer la importancia de la administración pública con las medidas de reajuste económico que se tomaron. La ideología en boga subvalora el papel del Estado en la sociedad, y la función pública no tiene el mismo prestigio de antes, como lo demuestra la baja remuneración que perciben los funcionarios públicos; durante los años ochenta, los salarios medios de los empleados públicos disminuyeron en 30\% (огт, 1992). 
Los empleados públicos gozan todavía de una importante estabilidad laboral, junto a cierto nivel de protección y redes de seguridad social que, aunque lejos de ser satisfactorias, los ponen en cierta medida a resguardo de las tendencias negativas más evidentes que operan en los mercados laborales de hoy. Además, no todos los funcionarios públicos perdieron posiciones. Un grupo, aunque pequeño, mejoró su ingreso y su condición social por el aumento de responsabilidades y la alta demanda de su tipo de especialidad en el sector privado. Es el caso, en particular, de los trabajadores de instituciones esenciales del nuevo sistema económico, como los encargados de la recaudación de ingresos fiscales y de la fiscalización y recolección de derechos aduaneros. También es el caso de la regulación del sistema financiero, como la banca, los seguros y las bolsas de valores, y de las instituciones creadas para regular las actividades privatizadas en los servicios sociales de utilidad pública y de previsión social. Como resultado, los salarios y las diferencias de status aumentaron en lo que solía ser un sector muy homogéneo. El aumento de la heterogeneidad del sector no es necesariamente una característica negativa. Puede inducir una mayor eficiencia en el sector público si se introducen incentivos a la productividad del trabajo, como está sucediendo en las áreas de educación y salud. Además, si se puede retener fuerza trabajadora altamente calificada en el servicio público porque los salarios y las condiciones laborales son competitivos con los del sector privado, aumentará la calidad del producto. Las perspectivas de movilidad social y de mejoramiento del status de una parte de la fuerza de trabajo del sector público, aunque promuevan diferencias salariales, pueden traducirse en un desempeño global más eficiente del sector en su conjunto.

\section{La heterogeneidad social y la privatización de empresas públicas}

La segunda característica del nuevo papel del Estado es el proceso de privatización de las empresas públicas que ha ocurrido en toda América Latina. La privatización ha tenido un impacto importante en el funcionamiento de los mercados de trabajo, sobre todo en algunas de sus características institucionales. La flexibilidad del mercado del trabajo se ha logrado por diversos medios. El primero es una mayor libertad para despedir trabajadores. En casi todas las empresas públicas que se privatizaron se prescindió de una proporción de la fuerza de trabajo, con lo cual, al comienzo, aumentó el desempleo. Por cierto, un proceso similar se registraba en el sector privado. Algunos de esos trabajadores no han sido capaces de encontrar un trabajo estable y han descendido de condición, alternando períodos de empleo y subempleo. Otros han encontrado trabajo similar al que hacían en las empresas públicas. Por último, los demás se convirtieron en empresarios, crearon sus propias empresas, a menudo ligadas funcionalmente a las grandes empresas que antes les daban empleo formal. De esta forma, cuando trabajadores y empleados en general son despedidos de las empresas privatizadas, algunas de sus funciones anteriores, quizás algunas esenciales, se contratan fuera a pequeños subcontratistas. Así, llega a establecerse una cadena de subcontratistas. Estas modalidades institucionales han sido tradicionales en algunos sectores económicos, como la construcción. Hoy se presentan también en los sectores primarios, los servicios básicos, las telecomunicaciones y los servicios financieros.

La subcontratación externa da una mayor flexibilidad a las empresas, permitiéndoles responder adecuadamente a las fluctuaciones del entorno económico. Aun cuando no ha habido una macroevaluación completa de este proceso en términos de ingreso y empleo, los estudios de casos nacionales muestran que su impacto es heterogéneo. Por ejemplo, en el sector minero estatal de Chile, donde se han producido despidos masivos para reducir los costos de producción, muchos trabajadores han sido recontratados como subcontratistas. Aunque indudablemente han perdido estabilidad laboral y beneficios no salariales de importancia, han ganado en términos de condiciones de trabajo y menores tasas de accidentes (orT, 1997b). Por otro lado, en muchos otros casos las condiciones de ingreso y empleo se han deteriorado. Abundan empleos precarios en los diferentes países y sectores en los que la subcontratación se convierte en característica común del mercado del trabajo. En estos casos, los trabajos temporales, la falta de previsión social y la inexistencia de sindicatos, negociación colectiva y mecanismos de capacitación parecen ser la norma, aunque pueden también acompañarse de salarios más elevados.

\section{Las empresas transnacionales y sus efectos sociales}

La privatización de empresas públicas ha aumentado la presencia de las empresas transnacionales. Esto ha generado un nuevo estrato gerencial, que se caracteriza por ingresos muy altos, una perspectiva internacional (frente a los intereses nacionales) y una ideología 
corporativa que se basa en la idea de que la globalización redefine límites nacionales e intereses locales. Este estrato se encuentra no sólo en las empresas privatizadas, sino también en otras empresas privadas, concentrándose especialmente en el comercio, los servicios financieros y la industria. Una consecuencia de la transnacionalización de estos gerentes es que tienden a aplicar a las relaciones laborales un estándar internacional, desconociendo las características nacionales y locales. En muchas ocasiones son accionistas de la compañía, lo que los hace, de hecho, identificarse pragmáticamente con los intereses de la empresa. Pero al nivel macro, también se preocupan de hacer que todo el sistema económico funcione, en la medida en que los resultados de los mercados de capitales y financiero se vinculan directamente con sus propios ingresos totales (Lo propio ocurre con los que participan en los fondos de pensiones privatizados cuando éstos han sido autorizados a invertir en acciones).

Una forma específica de presencia transnacional es la maquila: la transferencia de determinadas partes del proceso productivo de un país a otro, habitualmente aprovechando los menores costos laborales cuando éstos tienen impacto importante en los costos totales de producción. (El costo de la mano de obra representa el 54\% de los costos totales de la maquila típica de América Central, donde los costos de la mano de obra son inferiores en 3.5 veces a los de Estados Unidos). En algunas partes de América Latina esta forma de producción tiene importancia creciente. En América Central, la maquila proporciona 250.000 empleos (400.000 si se incluye la República Dominicana), lo que representa el $30 \%$ del empleo del sector industrial formal, $20 \%$ del valor agregado de las exportaciones y cerca del 10\% del PNB industrial (Gitli, 1997). Por ello, el impacto de la maquila ha sido significativo y, en algunos casos, los grupos más postergados del mercado de trabajo, principalmente mujeres, han sido los favorecidos. Ha llegado a ser un medio de aumentar la participación en la fuerza de trabajo; se trata de un estrato social que depende claramente de las actividades transnacionales de empresas del mundo desarrollado, favorecidas por la globalización de las economías nacionales.

El mismo estudio revela que las normas laborales y hasta los derechos humanos no siempre se respetan. Están muy difundidos los talleres donde se explota la mano de obra, aun cuando hay una presión creciente para que las empresas extranjeras cumplan al menos con las normas mínimas de sus países de origen. Queda por ver si será posible cuando los bajos costos de la mano de obra son la razón de ser de la maquila.

\section{Las microempresas y el sector informal}

Las microempresas, mucha de ellas informales, han sido en general la fuente principal de empleo en América Latina en la última década. Son importantes los efectos sociales de esta tendencia. Para comenzar, se ha debilitado la fuerza de trabajo asalariada que tradicionalmente formaba el movimiento laboral. El obrero de las empresas industriales medianas y grandes ha sido crecientemente sobrepasado en número por los asalariados de la microempresa. Otros se convirtieron en contratistas independientes, principalmente en los sectores del comercio y los servicios.

La evolución de las microempresas ha reflejado, en muchos casos, su relación con la economía internacional. Mientras una gran mayoría abastece los mercados nacionales, una parte está hoy vinculada a la economía mundial a través de las exportaciones. Algunos autores han sostenido que esta "neoinformalidad" caracteriza los mercados laborales del presente, en especial cuando las empresas forman parte de la cadena de maquilas de las empresas extranjeras y cuando encuentran determinados nichos en mercados externos específicos (Pérez-Sáinz, 1996). Pero en todas ellas no existe una división importante entre capital y trabajo.

En esta etapa, parece importante recordar que la evolución de la estratificación social en América Latina fue, hasta el decenio de 1970, un proceso relativamente lineal en que la fuerza de trabajo experimentaba una clara movilidad social estructural. De hecho, las investigaciones de Germani, Stavenhagen y Medina Echavarría, entre otros, sugerían que existía una tendencia secular a la movilidad ascendente, desde ocupaciones de baja productividad a las de mayor productividad. El proceso se veía más bien como un cambio entre sectores — de la agricultura a la manufactura y a los servicios- y entre categorías ocupacionales - de obreros a trabajadores no manuales- (véase Filgueira y Geneletti, 1981).

Esto ya no parece seguir siendo así. Este artículo sostiene que uno de los resultados de las políticas de ajuste y de la globalización de las economías nacionales ha sido el desarrollo de características heterogéneas dentro de los segmentos del mercado de trabajo, y este fenómeno se aprecia mejor cuando se analiza el sector de la microempresa. En términos económicos y sociales, "pequeña escala" tiene significados distintos. 
Algunas microempresas están altamente capitalizadas, se vinculan con mercados dinámicos, están insertas en los sectores de punta y tienen una fuerza de trabajo crecientemente calificada, mientras que otras son todavía convencionales en términos de uso de capital y trabajo. De ahí que la heterogeneidad haya aumentado como resultado de las tendencias económicas recientes: los empleados en empresas vinculadas a los estratos desarrollados se han beneficiado de oportunidades de ingreso y empleo (aunque no necesariamente de calidad del empleo), y los que siguen desconectados del motor principal de la economía se han quedado atrás. Siguen trabajando en empleos de baja productividad, con baja calificación y escasa seguridad laboral.

\section{Análisis sectorial}

Las tendencias heterogéneas del mercado de trabajo y su impacto social se pueden también observar al nivel sectorial. Los estratos sociales varían según la forma de vinculación de las empresas con el resto de la economía (nacional e internacional). El desarrollo de la agricultura ilustra claramente este aspecto. Los sectores agroindustriales que han crecido sobre la base de mercados externos han requerido diferentes tipos de fuerza de trabajo y han generado un conjunto de ocupaciones nuevas que antes no existían en la agricultu-

\section{IV}

\section{Conclusiones}

No puede aislarse la globalización de las demás políticas que la han acompañado durante los últimos veinte años. Constituyen un bloque de políticas que es muy difícil de descomponer, empírica o analíticamente. Tres procesos se han analizado: los de globalización, privatización y desregulación. Los efectos sobre la estratificación social, principalmente a través de su impacto sobre los mercados de trabajo, han sido el centro de nuestro análisis porque la estructura ocupacional es la base del sistema de estratificación.

La principal conclusión es que la estructura social en América Latina ha estado bajo tensión durante el período de la reforma. Esta tensión ha afectado la coherencia social y se ha traducido en un aumento de la heterogeneidad. Como en todos los procesos, ha habido quienes ganan y quienes pierden. La diferen- ra tradicional. Primero, necesitan una fuerza de trabajo relativamente capacitada y entrenada. Segundo, generan trabajos mayoritariamente temporales. Tercero, han abierto nuevas alternativas de trabajo asalariado para quienes antes estaban desocupados o no eran económicamente activos, sobre todo mujeres. El aumento de su participación en el mercado de trabajo ha traído consigo cambios en la organización de la familia y en la distribución interna de roles. Por último, la mayor parte de estos trabajos son remunerados según su productividad. Comparemos estas características con las del hombre trabajador asalariado permanente ocupado en la agricultura y dedicado a cultivos tradicionales, con escasa capacitación, y que, con suerte, gana el salario mínimo. Por lo tanto, en la misma categoría ocupacional, la variedad de ocupaciones ha aumentado en términos de la oferta de trabajo requerida, sus características personales, las normas de productividad y la permanencia en el mercado de trabajo. En suma, podemos decir que la heterogeneidad ha sido una característica tradicional de la agricultura, por ejemplo, al coexistir la economía de plantaciones con la campesina. La diferencia hoy es que este fenómeno se observa al interior de las categorías ocupacionales de modo que, por ejemplo, el trabajo asalariado es heterogéneo, dependiendo de si el sector específico está o no vinculado al sistema económico más amplio. cia ahora es que los cambios son significativos y afectan estructuralmente, no sólo el presente, sino también el futuro de la población, la sociedad y las naciones.

El cambio, especialmente en el decenio de 1990, no fue del todo negativo. La pobreza tendía a disminuir y los pobres han mejorado en términos de ingresos. En cambio, la equidad se ha deteriorado. Los vencedores son una minoría, mientras que los demás -no sólo los pobres sino también los grupos de ingresos medios- se han quedado progresivamente rezagados en términos relativos. Los efectos del conjunto de políticas sobre el empleo y los ingresos del trabajo, así como la desigualdad de oportunidades, han demostrado ser un factor importante de este resultado. La tendencia resulta perversa en una región con la desigualdad más alta del mundo. 
No parece haber pruebas suficientes para sostener que el bloque de políticas ha tenido efectos concentradores. La mayoría de los impactos positivos beneficiaron a sectores que ya estaban en los tramos superiores de la distribución del ingreso: favoreció a los relativamente más ricos. Los efectos negativos que se han registrado en el mercado de trabajo como resultado del impacto de las políticas - precarización de las condiciones de trabajo (falta de contratos o seguro social, etc), terciarización e informalización, así como el desempleo- se han concentrado mayormente en los sectores que ya eran relativamente más pobres. De esta forma, las diferencias han aumentado. Los asalariados pueden hasta tener salarios más altos que en el pasado reciente, pero sus empleos son, en muchos aspectos, más precarios e informales. En estos casos, la condición de los trabajadores ha empeorado.

El estrato medio ha experimentado también descensos de sus niveles de bienestar. Describimos los impactos negativos del conjunto de políticas sobre el empleo público y su efecto consiguiente en la estratificación social. También es necesario añadir que los beneficios de las políticas sociales han disminuido, en la medida en que esas políticas se han concentrado más en los pobres a expensas de los grupos de ingresos medios. Como resultado, las clases medias están menos protegidas contra el desempleo y las malas condiciones de trabajo, las transferencias públicas (mediante subsidios) han disminuido y muchas ocupaciones que hasta antes les otorgaban importancia social, o han perdido su significación social o simplemente han desaparecido.

Esta distribución desigual de las ganancias y pérdidas parece ser mucho más lamentable ya que se había cifrado grandes esperanzas en los efectos positivos de la globalización - trayectoria que adoptaron todos los países latinoamericanos desde sus primeras etapassobre el crecimiento, la equidad y la integración social. El problema es, sin embargo, en qué medida la globalización ha impuesto distorsiones adicionales a una situación social ya desequilibrada. Para ponerlo en la perspectiva correcta, debe recordarse que el punto de partida no facilitó el proceso de ajuste social en un entorno de globalización, ya que la alta concentración de los ingresos y los graves desequilibrios macroeconómicos atenuaron cualesquiera efectos positivos que pudieron haber resultado de una integración más estrecha con la economía mundial. Entonces, el análisis debe centrarse en la situación posterior al ajuste.

Como se mostró, hubo cambios fundamentales en la estructura del empleo así como en los ingresos y en la calidad del empleo. La mayoría representa un deterioro para la situación de la población. El desempleo, característica nueva del escenario, contribuyó también a la exclusión social. La volatilidad asociada al funcionamiento de una economía más abierta agregó también inestabilidad a los empleos y los ingresos. No sorprende que la mayor preocupación de las personas hoy en la región sea el empleo y su mayor temor la inestabilidad y la pérdida de la protección laboral. Las demandas de mayor seguridad laboral durante los tiempos del ajuste fueron neutralizadas por la necesidad de ahorrar recursos y, en particular, de corregir los desequilibrios fiscales del gobierno.

La globalización agrega nuevas dimensiones al análisis económico de los mercados de trabajo, dado el vínculo más estrecho con el comercio, las finanzas y las comunicaciones a nivel internacional. El viejo análisis de centro-periferia que tanto influyó en la tradición intelectual de América Latina está dando paso al análisis de la dependencia y la marginalidad. Las vinculaciones son hoy no sólo más estrechas sino que lo son de naturaleza distinta. Ha aumentado la heterogeneidad.

Una forma directa de analizar esta relación es identificar los grupos de población que se relacionan más estrechamente con la economía global que con el país que habitan. Un caso interesante es el de México, uno de los países de la región que estuvo quizás más expuesto a la globalización en el pasado reciente. Castañeda (1996) identifica cuatro grupos que dependen directamente del comportamiento económico de los Estados Unidos, que suman entre el 20\% y el 25\% de la población mexicana. El primer grupo son los emigrantes mexicanos que viven en Estados Unidos. Se estima que constituyen una fuente de ingresos para 10 millones de residentes en México. Las remesas de ingresos son una contribución importante y exponencialmente creciente para las familias pobres (se estima que las remesas llegaron en 1998 a 5500 millones de dólares y que se han triplicado desde 1990). Un segundo grupo se relaciona con las exportaciones, incluida la maquila, que abarca 2500 establecimientos y beneficia a unos 2 millones de personas. Incluye también actividades relacionadas con la exportación en la agricultura y la industria manufacturera. Diversos ejemplos sirven de ilustración. General Motors de México, el principal exportador privado del país, está vendiendo $40 \%$ más automóviles en el exterior que en el mercado interno. Corona, el principal productor de cerveza, por cada botella que vende internamente, vende una en el exterior, y Cementos Mexicanos exportaba el 90\% de su producción en 1993. 
Un tercer grupo cuya supervivencia depende de los extranjeros es el sector del turismo. Se estima que unos 600000 mexicanos están empleados en esta actividad, lo que los aísla de las fluctuaciones internas. Por último, hay una gran cantidad de personas vinculadas con países extranjeros, como propietarios legales o ilegales, o simplemente porque ahorran, poseen activos, usan instrumentos financieros (como tarjetas de crédito) o estudian o trabajan temporalmente en el exterior en empleos profesionales y técnicos.

El análisis de Castañeda se puede extender al resto de América Latina, con diferentes proporciones pero con tipos de relaciones similares. Nuestro propio análisis muestra que no todos los sectores y las ocupaciones dentro de los sectores se han globalizado. Los efectos no han sido homogéneos. No todos los sectores se han visto afectados de la misma forma $\mathrm{y}$, entre sectores, el impacto ha sido diferente. Partes de la industria se han integrado a la economía mundial, mientras otras se han quedado atrás; por ejemplo, la agroindustria ha establecido vínculos fuertes con los mercados internacionales, en tanto que la agricultura campesina ha mantenido su autonomía. La ocupación se ha hecho más heterogénea tanto entre los sectores como al interior de ellos. Este es el caso de la maquila, el turismo y la subcontratación en la industria manufacturera. Las empresas y, por lo tanto, los dueños, los gerentes, los técnicos y la mano de obra calificada están incorporados a la economía global; los trabajadores no calificados, aunque mejor ahora que antes, están en situación precaria, que se caracteriza por bajos ingresos, inestabilidad y falta de protección. El desempleo se ha agregado a la exclusión social, particularmente de los jóvenes y de las mujeres.

Los efectos en los mercados de trabajo han producido cambios en la estructura social; el diferente grado de integración económica global de los distintos grupos de población trasciende los empleos y los ingresos, permeando las costumbres sociales. Las diferencias económicas y culturales se trasladan a comportamientos sociales diversos. La vida urbana ve cre- cer la segregación con nuevos ghettos para los ricos sobre los tradicionales para los pobres. Zonas cerradas, seguridad privada, centros comerciales y clubes exclusivos y hasta las escuelas conspiran contra la integración social. Cada día se dispone de menos espacios públicos, como parques y entretenimientos, que en el pasado promovían la interacción social. Escuelas separadas dividen a los niños por grupos sociales (Tokman y O’Donnell, eds., 1998). Como señala O'Donnell:

'El agudo, y creciente, dualismo de nuestros países obstaculiza gravemente el surgimiento de una solidaridad amplia y efectiva. Las distancias sociales han aumentado, y los ricos tienden a aislarse del extraño e inquietante mundo de los desposeídos. Los ghettos fortificados de los ricos y los apartados colegios de sus niños son testigos de su incorporación a las redes transnacionalizadas de la modernidad, así como del abismo que los separa de grandes segmentos de la población nacional'.

Las categorías sociales -instrumentos claves para el análisis de la estratificación social y la inclusión social- están siendo sometidas a un cambio conceptual fundamental. El problema hoy no es de clase, ni de ideología, ni de regiones (como sostiene correctamente Castañeda, 1996). No es de clase porque las familias de los migrantes o de los trabajadores de un mismo sector exportador se benefician igual que los dueños y los gerentes. No es de ideología, porque hoy las ideas están expuestas crecientemente y se alimentan de acontecimientos transnacionales en la revolución de las comunicaciones. Ni es cuestión del Norte contra el Sur, porque el nuevo escenario y el cambio ideológico mundial hacen más borrosas las divisiones del pasado. Trasciende todo esto. Los grupos sociales se estructuran por ocupaciones como en el pasado, pero los sectores tienden a perder significado cuando prevalece la heterogeneidad y, más importante, cuando las personas están cultural y económicamente relacionadas de manera distinta con los intereses nacionales e internacionales.

\section{Bibliografía}

Atkinson, A. B. (1996): Income distribution in Europe and the United States, Oxford Review of Economic Policy, vol. 12, $\mathrm{N}^{\circ} 1$, Oxford, Reino Unido, Oxford University Press.

Bhagwati, J. y V. Dehejia (1993): Free trade and wages of the unskilled: Is Marx striking again?, J. Bhagwati y M. Kodsters (eds.), Trade and Wages, Washington, D.C., American Enterprise Institute.
BID (Banco Interamericano de Desarrollo) (1998): América Latina frente a la desigualdad, Progreso económico y social en América Latina. Informe 1998-1999, Washington, D.C.

Castañeda, J. (1996): The Estados Unidos affair. Cinco ensayos sobre un "amor" oblicuo, México, D.F., Aguilar.

CEPAL (Comisión Económica para América Latina y el Caribe) (1997a): La brecha de la equidad. América Latina, el Caribe 
y la cumbre social, LC/G.1954/Rev.1-P, Santiago de Chile. Publicación de las Naciones Unidas, $\mathrm{N}^{\circ}$ de venta S.97.II.G.11. (1997b): Rasgos estilizados de la distribución del ingreso en cinco países de América Latina y lineamientos generales para una política redistributiva, serie Financiamiento del desarrollo, $\mathrm{N}^{\circ} 72$, Santiago de Chile.

(1999): Panorama social de América Latina, 1998, LC/G. 2050-P, Santiago de Chile.

Echeverría, R. (1985): Empleo público en América Latina, serie Investigaciones sobre empleo, $\mathrm{N}^{\circ} 26$, Santiago de Chile, Programa Regional del Empleo para América Latina y el Caribe (PREALC).

Filgueira, C. y C. Geneletti (1981): Estratificación y movilidad ocupacional en América Latina, Cuadernos de la CEPAL, $\mathrm{N}^{\circ}$ 39, Santiago de Chile, CEPAL.

Gitli, E. (1997): La industria de la maquila en Centroamérica. Informe para el Seminario Subregional de Empleadores de Centro América y República Dominicana, San José.

Krugman, P. (1995): The Age of Diminished Expectation, Cambridge, Massachusetts, MIT Press.

Lawrence, R. y M. Slaughter (1993): International trade and american wages in the 1980s: Giant sucking sound or small hiccup?, Brookings Papers on Economic Activity, $\mathrm{N}^{\circ} 2$, Washington D.C., The Brookings Institution.

Lustig, N. (1998): Pobreza y desigualdad: un desafío que perdura, Revista de la CEPAL, número extraordinario, LC/G.2037-P, Santiago de Chile, CEPAL.

Meller, P. y A. Tokman (1996): Chile: apertura comercial, empleo y salarios, Documento de trabajo, $\mathrm{N}^{\circ} 38$, Lima, Oficina de la OIT para América Latina y el Caribe.

OCDE (Organización de Cooperación y Desarrollo Económicos) (1994): Perspectivas del empleo, The OECD jobs study. Facts, analysis, strategies, París.

O'Donnell, G. (1998): Poverty and inequality in Latin America: Some political reflections, en V. E. Tokman y G. O'Donnell, eds.: Poverty and Inequality in Latin America: Issues and New Challenges, Notre Dame, Indiana, University of Notre Dame.

OIT (Organización Internacional del Trabajo) (1992): Memoria del Director General, Decimotercera Conferencia de los Estados de América Miembros de la Organización Internacional del Trabajo, Ginebra.

(1995): El empleo en el mundo 1995. Un informe de la OIT, Ginebra.

(1996): World Employment 1996/97: National Policies in a Global context, Ginebra. (1997a): NEWS Latin America and the Caribbean 1997 Labour Overview, Lima, Oficina de la OIT para América Latina y el Caribe.

(1997b): Chile: crecimiento, empleo y el desafio de la justicia social, Santiago de Chile, Equipo Técnico Multidisciplinario.

(1998): NEWS Latin America and the Caribbean 1998 Labour Overview, Lima, Oficina de la OIT para América Latina y el Caribe.

Paes de Barros, R. y otros (1996) Brasil: apertura comercial e mercado de trabalho, Documento de trabajo, $\mathrm{N}^{\circ} 39$, Lima, Oficina de la OIT para América Latina y el Caribe.

Pérez-Sáinz, J.P. (1996): De la finca a la maquila, San José, Facultad Latinoamericana de Ciencias Sociales (FLACSO).

Saavedra, J. (1996): Perú: apertura comercial, empleo y salarios, Documento de trabajo, $\mathrm{N}^{\circ} 40$, Lima, Oficina de la OIT para América Latina y el Caribe.

Sachs, J. y H. Shatz (1994): Trade and jobs in US manufacturing, Brookings Papers on Economic Activity, $\mathrm{N}^{\circ} 1$, Washington, D.C., The Brookings Institution.

Tokman, V. E. (1997): Jobs and solidarity: Main challenges for the post-adjustment Latin America, en L. Emmerij, ed., Economic and Social Development into the XXI Century, Washington, D.C., BID.

(1998): Jobs and welfare: Searching for new answers, en V. E. Tokman y G. O'Donnell, eds., Poverty and Inequality in Latin America. Issues and New Challenges, Notre Dame, Indiana, University of Notre Dame.

(1999): The labour challenges of globalization and economic integration, en E. Mayobre, ed., G-24. The developing countries in the international financial system, Boulder, Colorado, Lynne Rienner Publishers.

Tokman, V. E. y D. Martínez (1999): Costo laboral y competitividad en el sector manufacturero de América Latina, 1990-1998, Revista de la CEPAL, $\mathrm{N}^{\circ}$ 69, LC/G.2067-P, Santiago de Chile, CEPAL.

Tokman, V. E. y D. Martínez, eds. (1999): Flexibilización en el margen: la reforma del contrato de trabajo, Lima, Oficina de la OIT para América Latina y el Caribe.

Tokman, V. E. y G. O'Donnell, eds. (1998): Poverty and Inequality in Latin America. Issues and New Challenges, Notre Dame, Indiana, University of Notre Dame.

Williamson, J. (1990): Latin American Adjustment: How Much has Happened?, Washington, D.C., Institute for International Economics (IIE).

Wood, A. (1994): North-South Trade, Employment and Inequality, Oxford, Reino Unido, Clarendon Press. 